
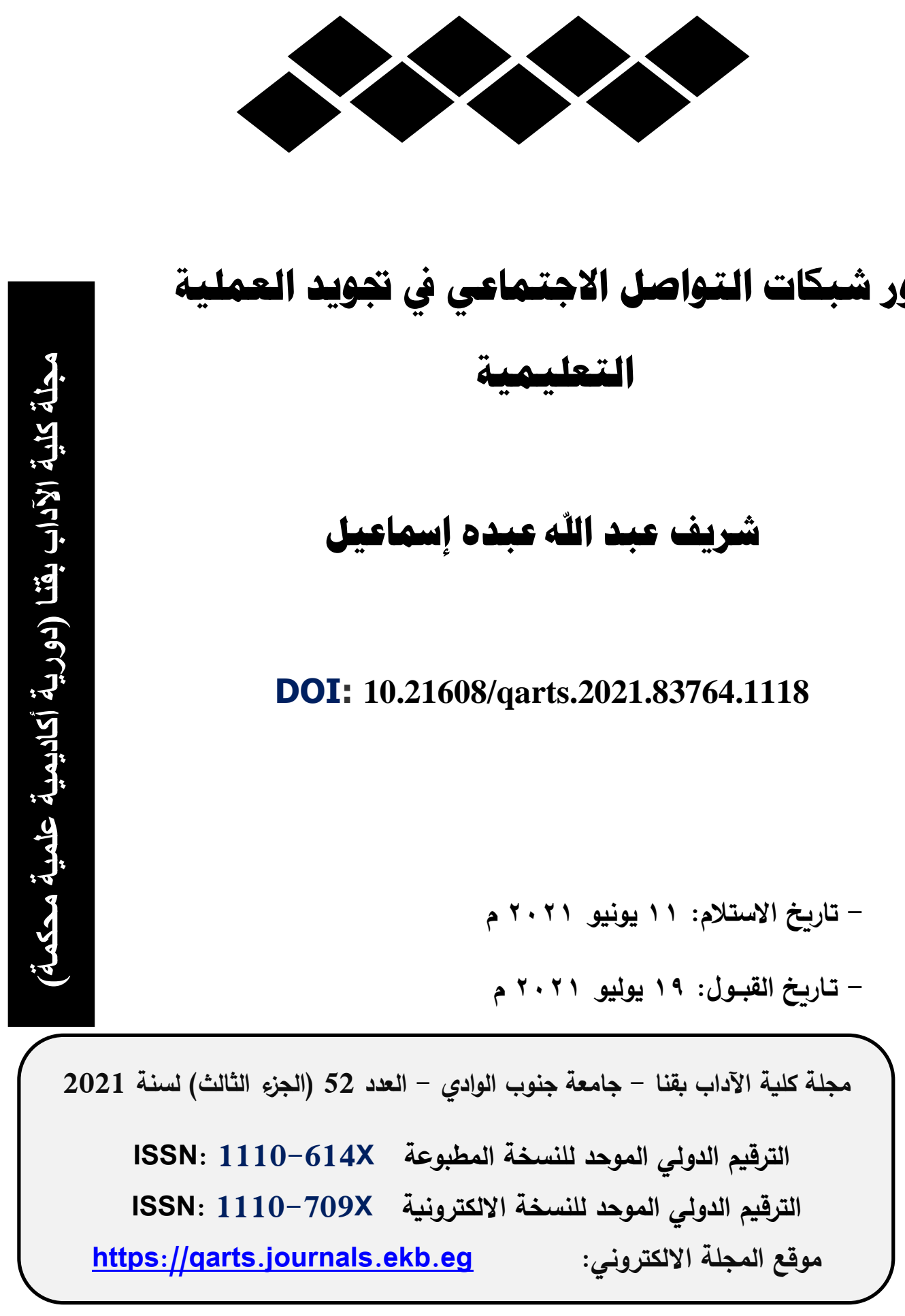
دور شبكات التواصل الاجتماعي في تجويد العملية التعليمية

شريف عبد الله عبده إسماعيل

shearf2030@gmail.com

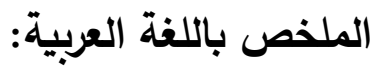

تعد شبكة الانترنت من أبرز مستحدثات تكنولوجيا الاتصـال التي فرضت نفسها

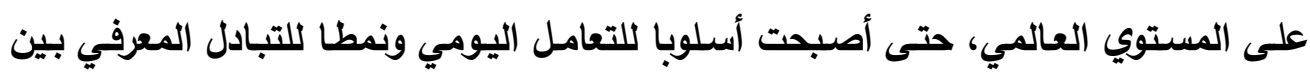

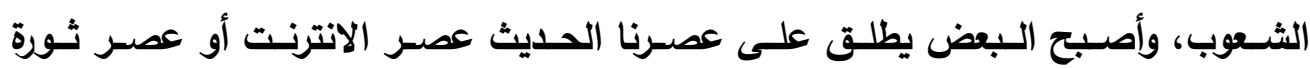
المعلومـات لمـا أحدثته هذه الثبكة مـن أثار عميقـة وتغيرات جذريـة في أسـاليب وإثـكال التواصل في شتي نواحي الحياة. وتعد جماعات التواصل الاكتروني عبر شبكات التواصل الاجتماعي واقع جديد في

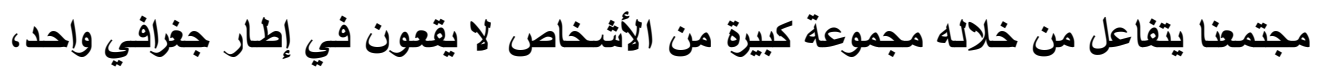
بل كل ما يجمع بينهم هو اهتمام مشترك وقد نجحت هذه الجماعات في استقطاب العديد من الأفراد للانخراط فيها واضحي بوابـة الاثتراك في هذه الجماعات لا يتطلب من الفرد

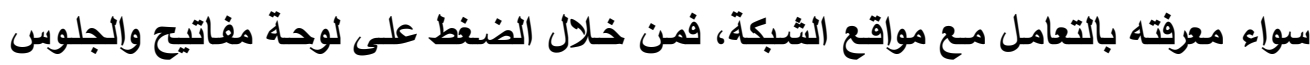

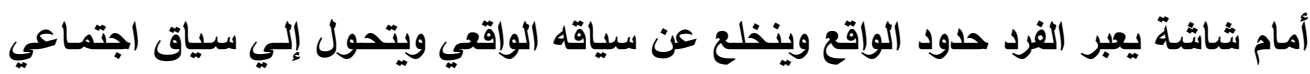
جديد هو الواقع الافتراضي.

الكلمات المفتاحية: التعليم الإكتروني، التدريب الإكتروني، شبكات التواصل الاجتماعي 
مقدمة البحث:

لم يعد العالم قرية صغيرة فحسب بل لقد أصبح أكثر قربا للفرد من ساعة اليد، ولقد

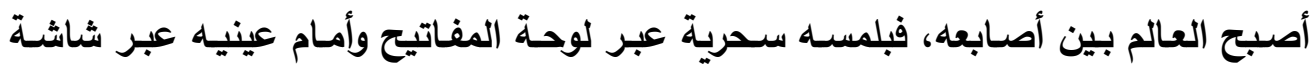

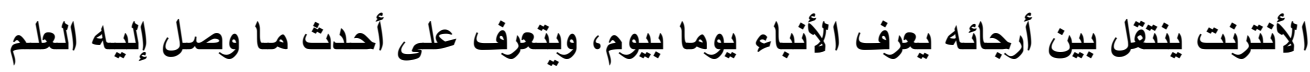
وينتقل بين المواقع المختلفة.

وتعد شبكة الأنترنت من أبرز مستحدثات تكنولوجيا الاتصال التي فرضت نفسهها

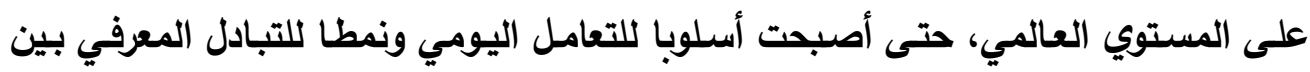

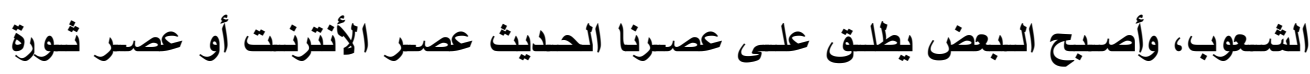

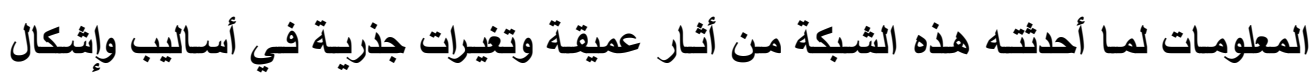
التواصل في شتي نواحي الحياة. وتعد جماعات التواصل الإكتروني عبر شبكات التواصل الاجتماعي واقع جديد في

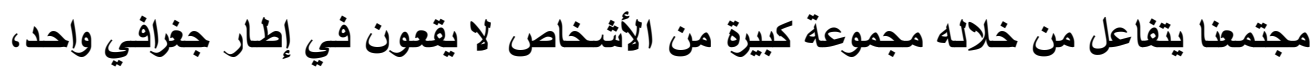

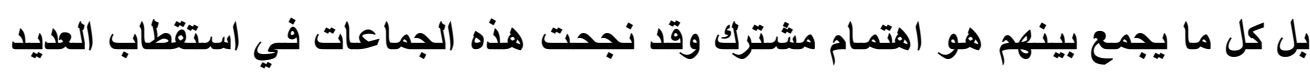

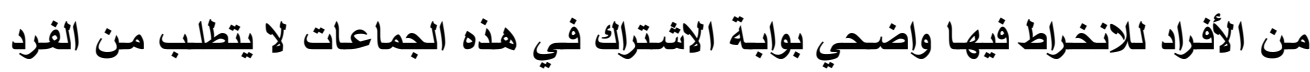

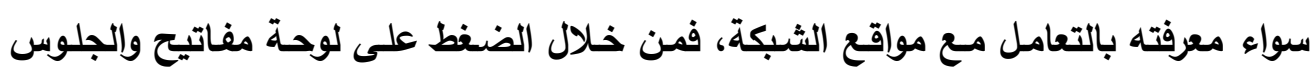

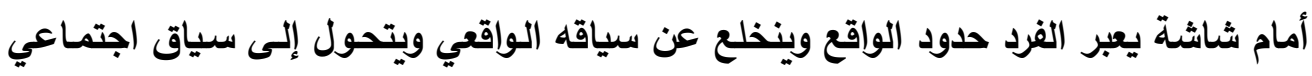
جديد هو الواقع الافتراضي. وفي هذا البحث سوف يتناول الباحث عرض مفهوم وأهمية ومميزات وسلبيات وخدمات

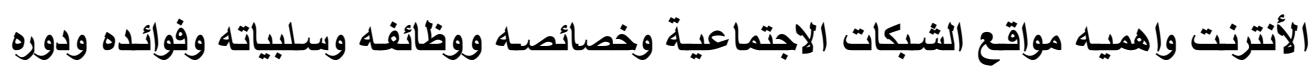

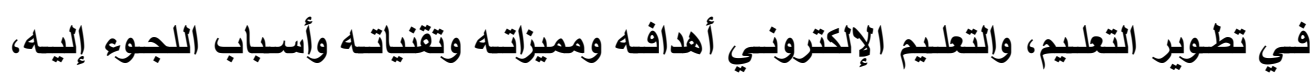
والتدربب الإكتروني أهميته وأهدافه ووسائله وعناصره ومميزاته الإكيته

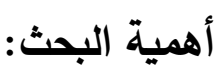

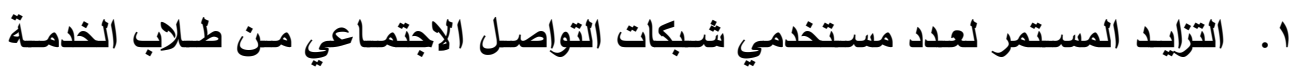

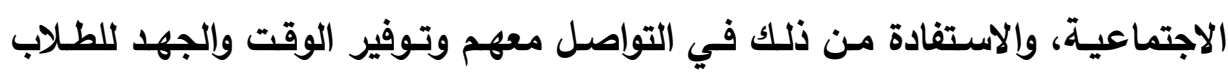
والمشرفين. r. اهتمام الدولة بجودة التعليم بصفة عامة وتعليم الخدمة الاجتماعية بصفة خاصة. 
r. الخدمة الاجتماعية كمهنة تتواكب مـع المتفيرات المعاصرة ومنها التكنولوجيا الحديثة المتمثلة في شبكات التواصل الاجتمـاعي، ومن ثم لابد من تطوير التدريب الميداني بما يتناسب مع تلك المتغيرات.

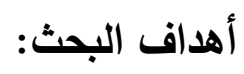

الهدف الرئيسي للبحث: "التعرف على دور شبكات التواصل الاجتماعي في تجويد العملية التعليمية" التهونية

وينبثق من الهاف الرئيسي للاراسة مجموعة من الأهداف الفرعية منها:

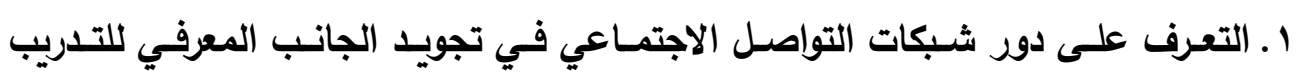
الميداني لطلاب الكليات وإلمعاهد العليا للخدمة الاجتماعية.

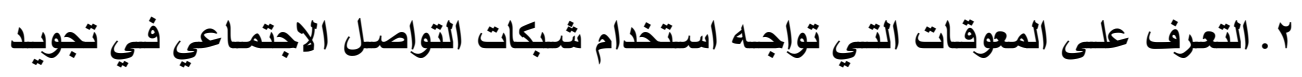

$$
\text { برامج التدربب الميداني. }
$$

r. التعرف على المقترحات التي يمكن من خلالها تفعيل دور شبكات التواصل الاجتماعي

$$
\text { في تجويد برامج التدريب الميداني. }
$$

ء. التوصل لآليات تفعيل الإقبال على شبكات التواصل الاجتماعي لتجويد التدريب الميداني

للكليات والمعاهد العليا للخدمة الاجتماعية.

أولا: التعليم الإلكتروني:

أطلت علي العالم بعض المتغيرات التي أوجبت ضرورة إعادة التفكير في منظومـة

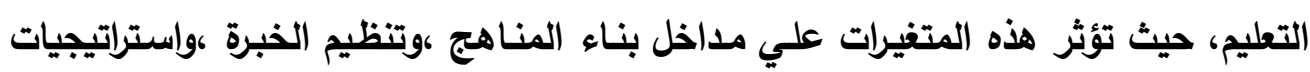
التدريس، بالإضافة إلي أساليب التقويم.(')

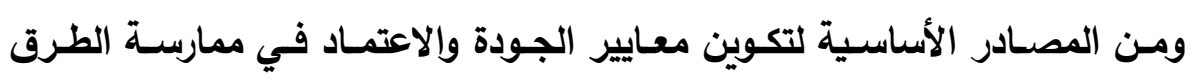

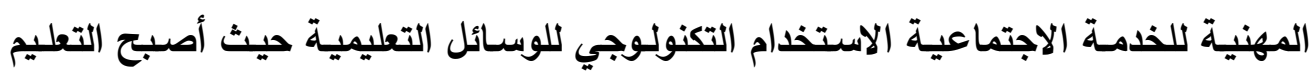

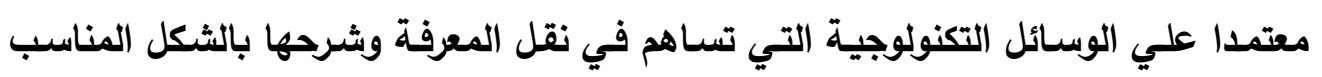

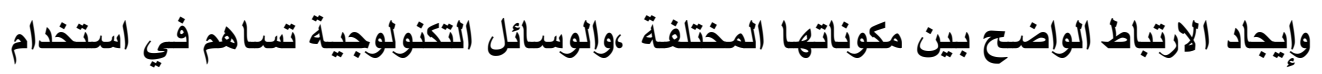

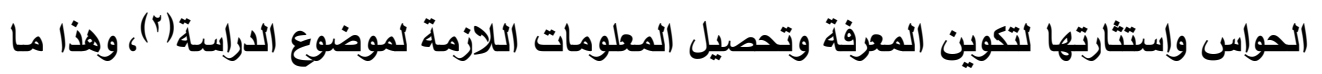

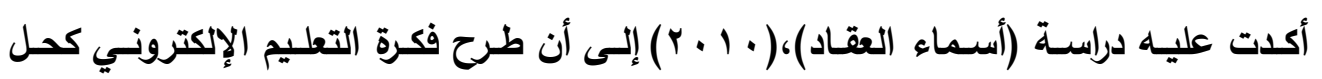

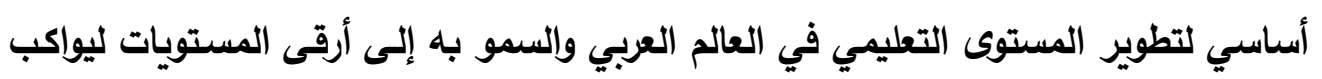


التطور التكنولوجي الهائل، والعمل على تحيد وجهة الجيل القادم نحو مجتمع نـاجح فعال

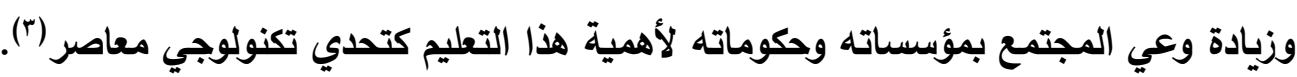

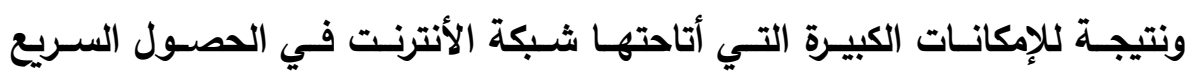
للمعلومات استفاد العديد من جامعات العالم منها كمصدر هام من مصادر التعليم ، حيث

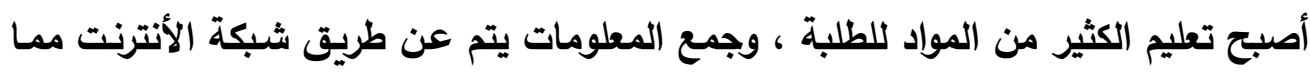

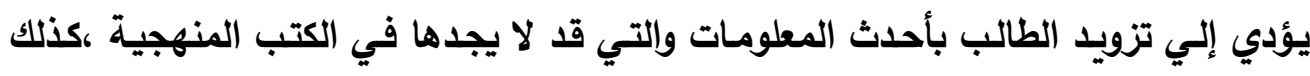

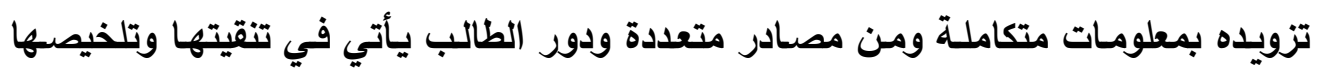

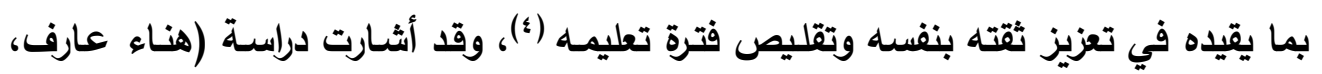

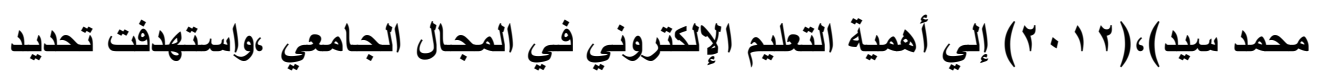

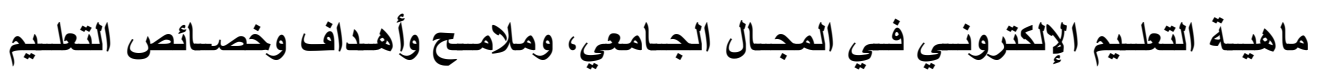
الإكتروني، والمعوقات التي تواجها،، والمقترحات المرتبطة باليات تفعيل التعليم الإكتروني بالمجال الجامعي في ضوء المتغيرات المحلية والعالمية (•).

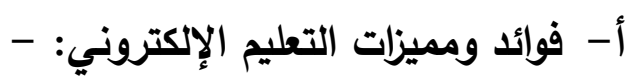
ومع تعاظم ثورة المعلومـات، وتزايـ كمية المعلومـات، والبيانات المنقولية والمتبادلـة

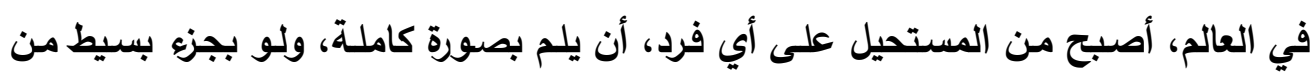

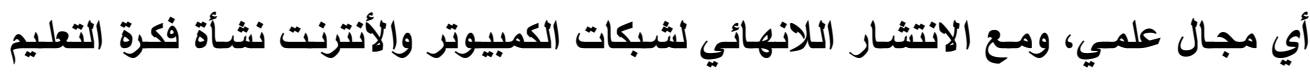

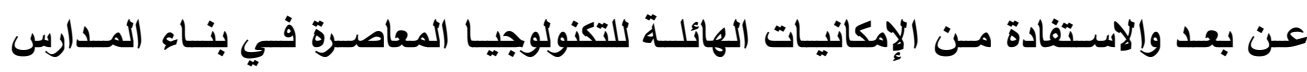
والجامعات الإلكترونية لما لها فوائد ومميزات يمكن تلخيصها في النقاط التالية:

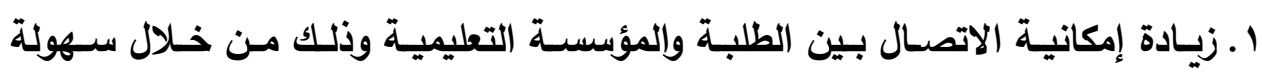
الاتصال ما بين هذه الأطراف في عدة اتجاهات مثل مجالس النقاش والحوار والبريد الإككتروني وغرف الحوار ،ويري الباحثون أن هذه الأثثياء تزيل، وتحفز الطلاب(؟).

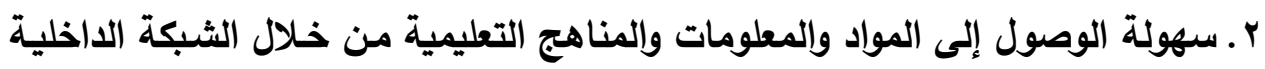

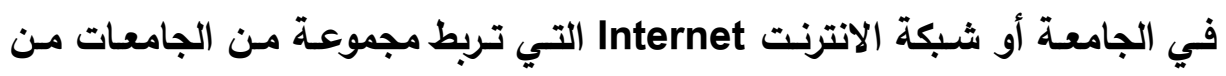

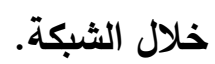
r. توفير تكاليف الكتب، والمطبوعات، والأورلق وإستخدام هذه الموارد المالية في أمور أخري. 
ـ ـ إمكانية التعديل والتحديث الفوري للمقررات الدراسية وتعميم هذه التعديلات على جميع

$$
\text { الطلاب والمعلمين. }
$$

هـ إرجـاع الأثـر Feedback الفـوري للدارســين، وإجـراء المناقثـات المباشــرة بـين

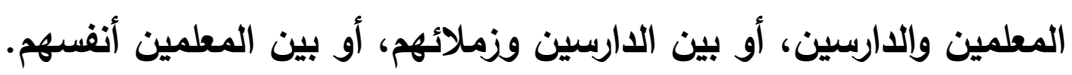

4. إجراء الاختبارات عبر الثبكات وتقييم نتائجها الكتر ونيا وبصورة تلقائية. V. الوصول إلي كم هائل من المعلومات والبيانات الحديثة عن طريق الشبكات الثبات المتعددة

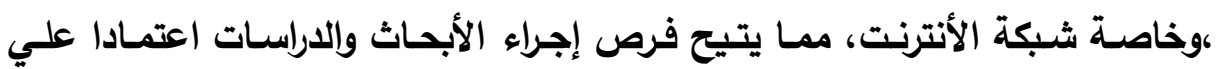

$$
\begin{aligned}
& \text { (v). المعلومات الحديثة } \\
& \text { ب-تقنيات التعليم الإكتروني: }
\end{aligned}
$$

يشها هذا العصر تطورات مستمرة في الوسـائل التكنولوجية التي يمكن استخدامها في

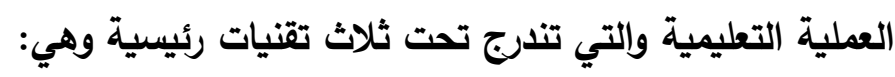

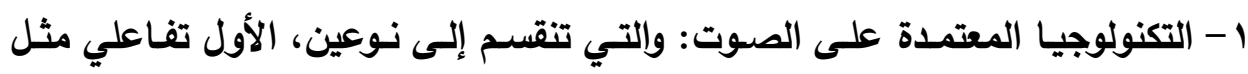
المؤتمرات السمعية والثراديو قصير الموجات، والثانية فهي أدوات صوتية ساكنة مثل الأشرطة السمعية والفيديو. r - تكنولوجيا المرئيات (الفيديو): يتنوع استخدام الفيديو في التعليم، ويعد من أهم

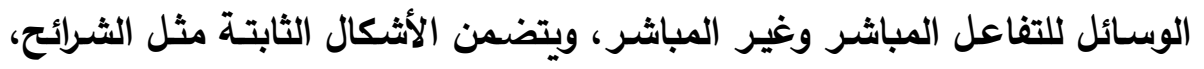

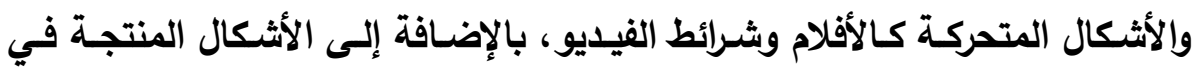

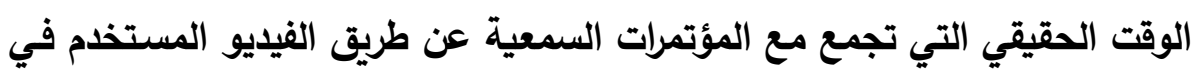

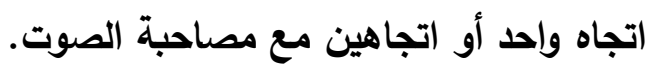

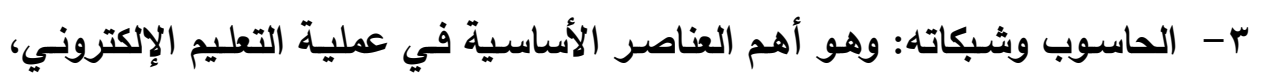
فهو يستخدم في عملية التعلم بثلاثة أثكال وهي: - - التعلم المبني على الحاسوب والتي تتمثل بالتفاعل بين الحاسوب والمتعلم فقط. -

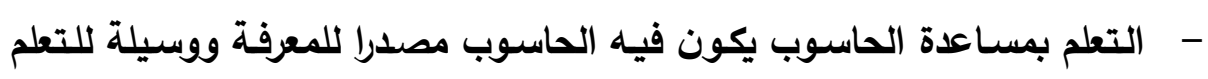
مثل استرجاع المعلومات أو مراجعة الأسئلة والأجوبة. - التعلم بإدارة الحاسوب حيث يعمل الحاسوب علي توجيه وإرشاد المتعلم (^). ج-أهداف التعليم الإكتروني: 
بداية فإن الأهداف المأمولة من التعليم الإكتروني كثيرة ومتنوعة منها:

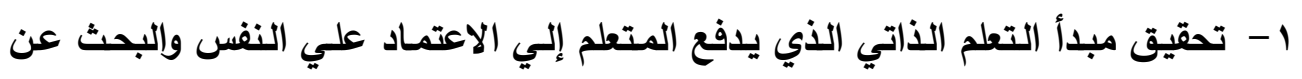
المعرفة والمعلومات من خلال المصادر المختلفة.

ץ- تـوفير فرص التعليم المستمر للأفراد الـذين يرغبـون في زيـادة حصيلتهم الثقافيـة

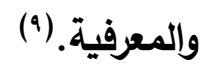

r- التطوير المهني والتكنولوجي للكادر الأكاديمي والإداري في حقل التعليم الإكتروني التفاعلي. ع - التطبيـق الفعلـي والعملـي للوسـائل ،والبـرامج ،والأنظمـة المسـتخدمة فـي التعلـيم

$$
\text { الإلكتروني (10). }
$$

$$
\text { د - أسباب اللجوء إلى التعليم الافتراضي (الإلكتروني): }
$$

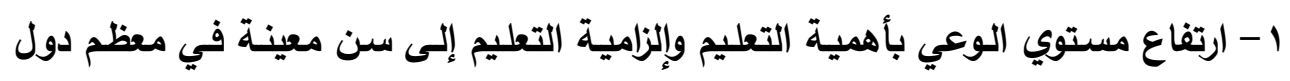

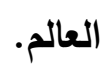

r - الحاجة المستمرة إلى التعليم والتدريب في جميع المجالات. r- عدم المقدرة على تلبية الطلب على الخدمة وقبول من يرغب في الدراسـة، وازلدحام الفصول الاراسية والنقص النسبي في عدد المدرسين.

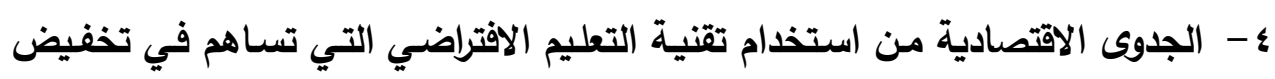

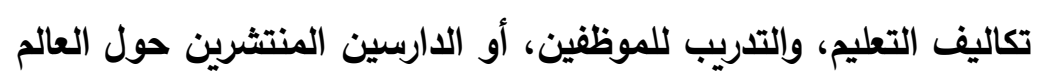

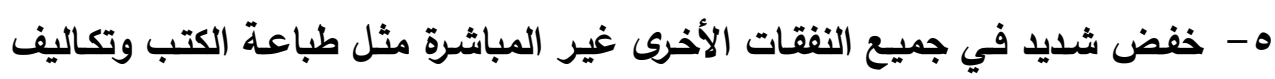
السفر ومصاريف ونفقات الإقامة التي تترتب على السفر وما شابه ذلك.

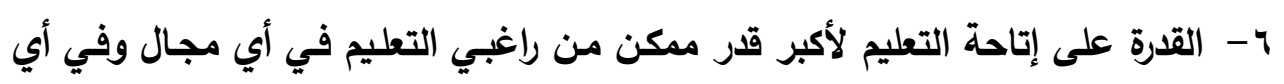
بلد. V- التخلص من الكثير من المشاكل الاجتماعية التي تنجم عن التعليم التقليدي، مثل الفروقات بين الطلبة (المظهر والملابس) (11). ثانياً: التدريب الإلكتروني: "مع إطلالمة القرن الجديد، مـع تقدم المعارف والمهارات والأسـاليب اللازمسة للوفاء بمختلف متطلبات العملية التدريبية ،والتواصل المتلاحق في شبكات الكمبيوتر والأنترنت 
والمعلومات لقد أحدثت التطورات التي شـاهدتها مجالات تقنية المعلومـات والاتصالات نقلة

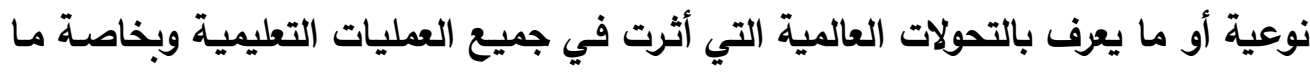

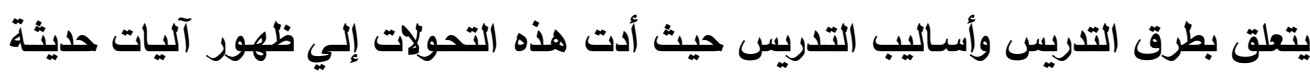

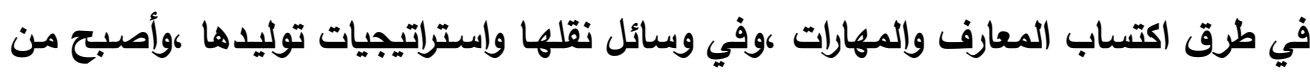

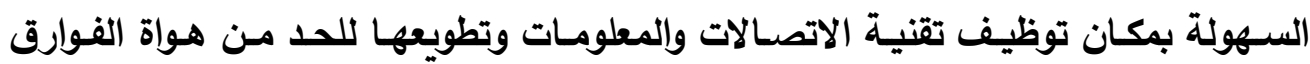

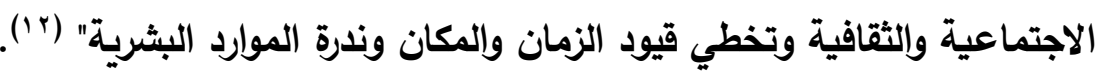

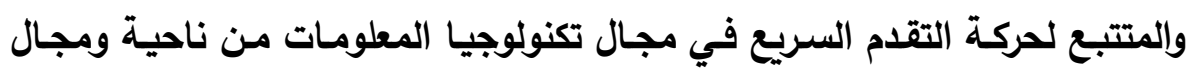
تكنولوجيا التعليم مـن ناحيـة أخري ،ويلاحظ إن تزاوجـا قد حدث بين المجـالين ،وقد أدي

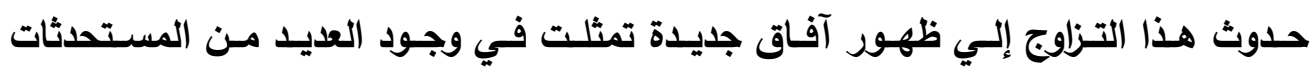

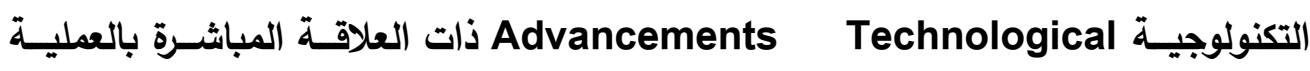
التعليمية ، ومن هذه المستحدثات التعلم الإكتروني_E-leaning وإلتدريب الإكتروني (r').

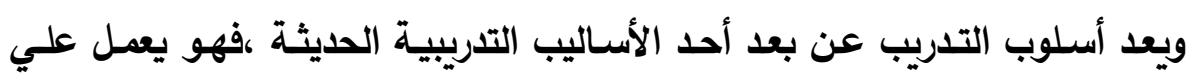

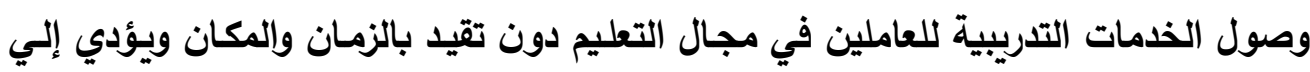

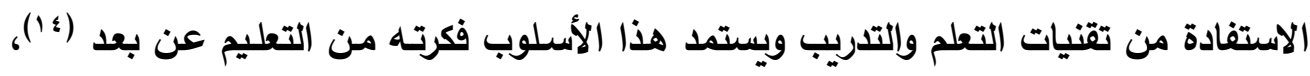

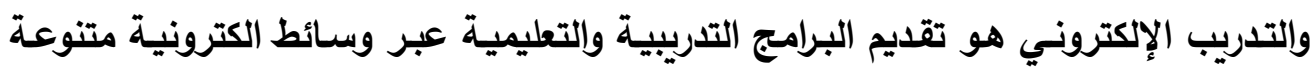

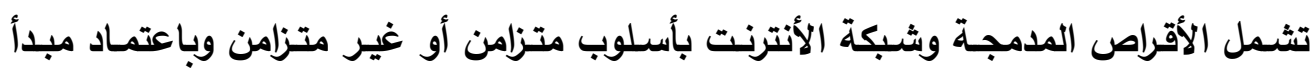

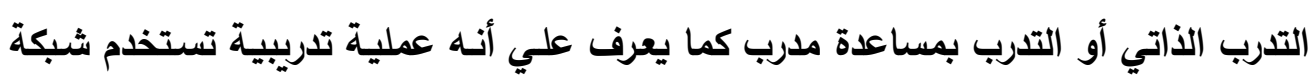

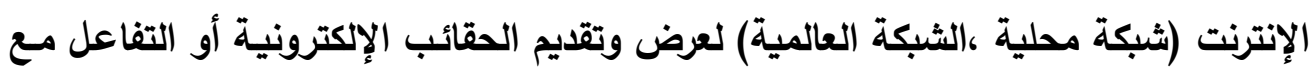

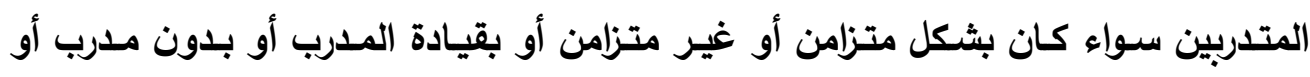

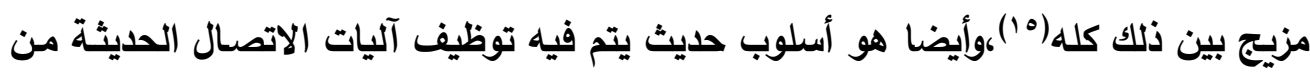
حاسوب وشبكاته ووسـائطه المتعددة من صوت وصورة ،ورسومات وآليات بحث ومكتبات

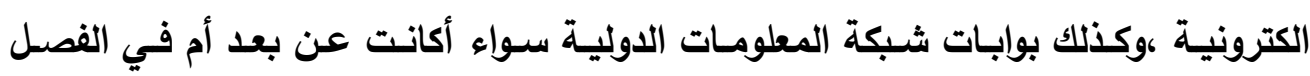

الدراسي (17).

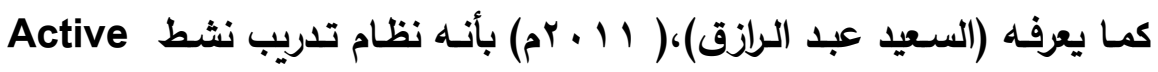
Training

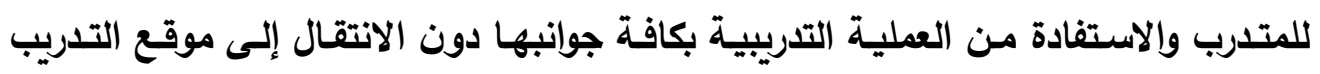

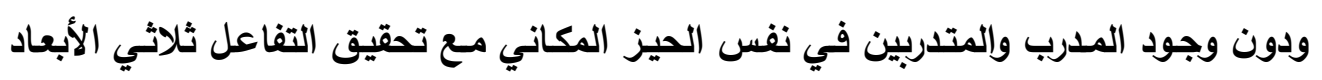


(المحتوى التدرببي الرقمي - المتدبين - المدرب والمتدربين) وإدارة العملية التدريبية بأسرع

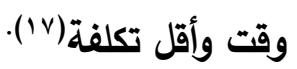

ونظرا لوجود سلبيات للتدريب التقليدي تتمثل في غياب التخطيط الاستراتيجي لنظم

وبرامج تدريب الأخصائيين الاجتماعيين في مصر، حيث أن موضوعات التدريب لا يتم

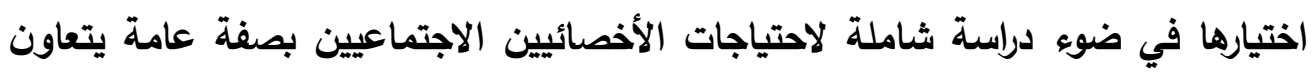

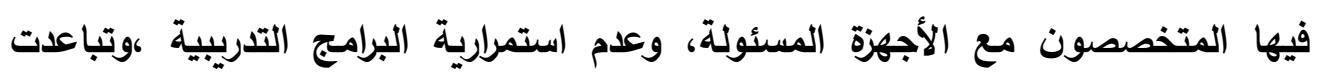

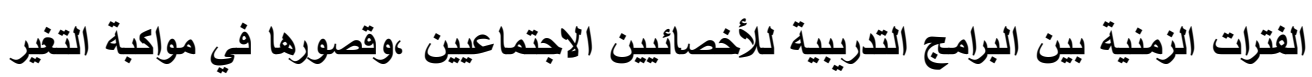

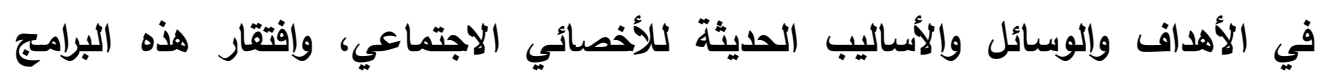

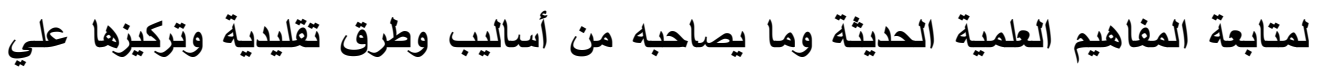
المدرب وفرض شخصيته علي المتدربين، مع اعتمادها علي أساليب بعينها كمحاضرات الثفهية أو المكتوبة وحلقات النقاش وقليل من ورش العمل غير المجدئية المبلية، ونمطية أساليب

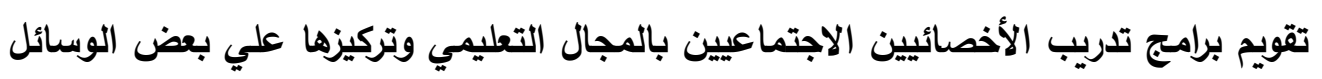

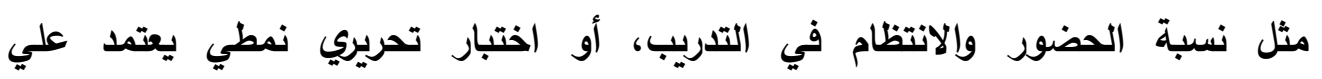

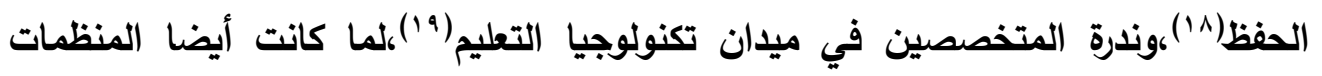

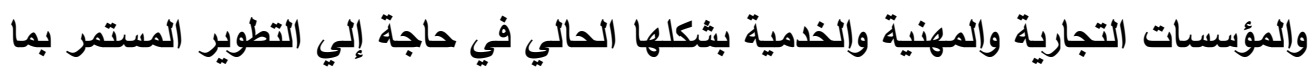
يضمن الارتقاء بالمورد البثري من خلال الاعتماد علي التكنولوجيا الحديثة ،ولما كانت الخدمة الاجتماعية تمثل إحدى المهن التي تعتمد علي التدريب في تطوير الثخصية

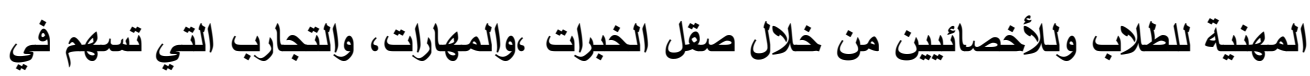

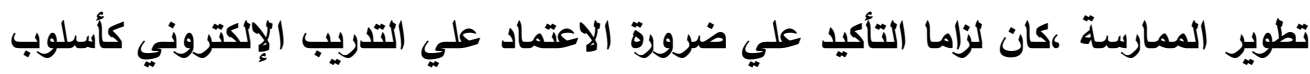

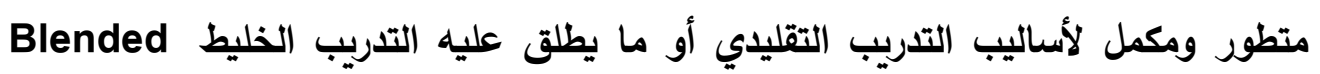
حيث ممارسات المزج بين أساليب التدريب التقليدي مع لمابي التدريب

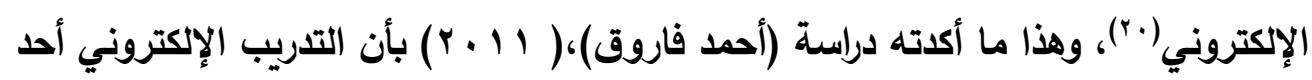

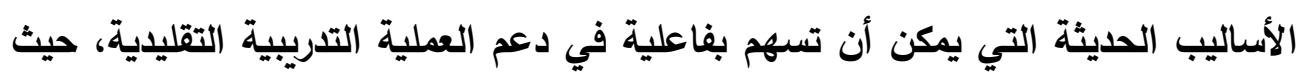

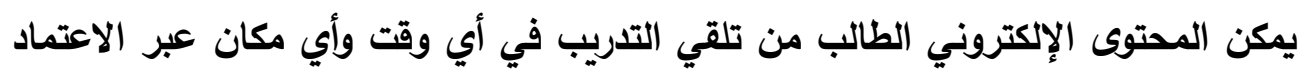

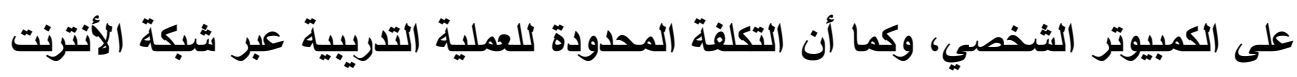

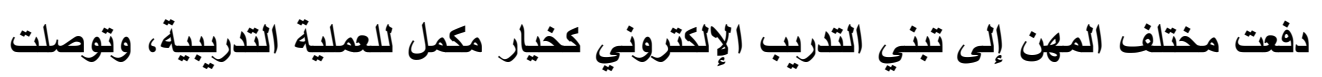
إلي النتائج التالية اتجاهات الطلاب والمشرفين نحو التدريب الإكتروني بنوعيه المتزامن 
وغير المتزامن في الذدمة الاجتماعية تعد متوسطة القوة ،وأن التدريب الإكتروني في

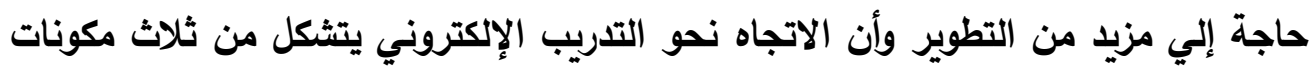

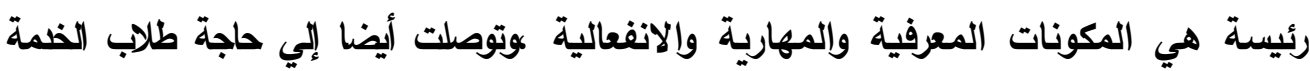
الاجتماعية إلي تدعيم الاتجاهات نحو التعليم الإكتروني (21) . لذلك تم اللجوء إلي التدريب الإكتروني للأخصائيين الاجتمـاعيين بالمجـال التعليمي

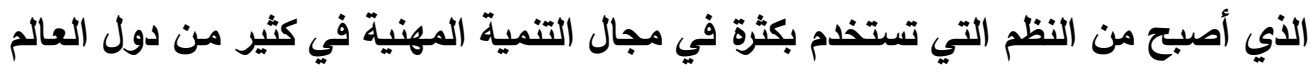
وذلك من منطلق حرص هذه الدول علي الإفادة من تقنيات ، ووسـائل تكنولوجيا المعلومـات

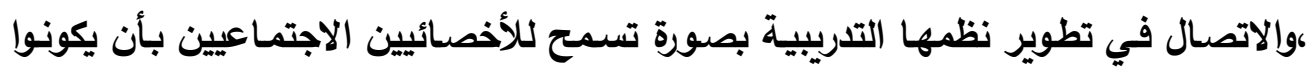

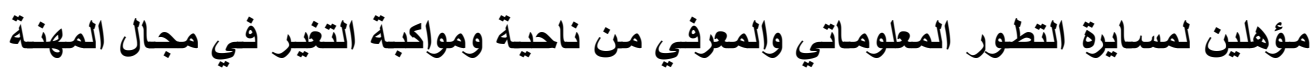

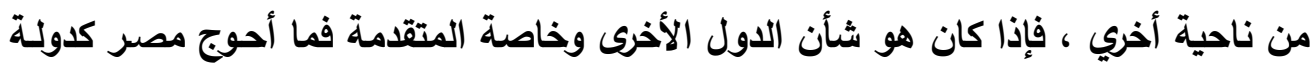

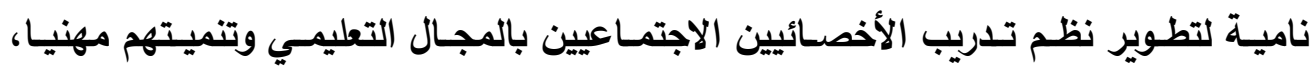

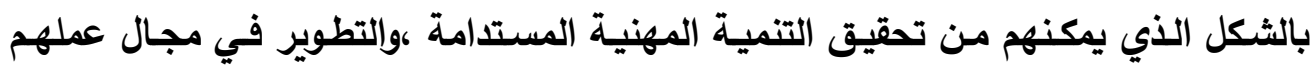

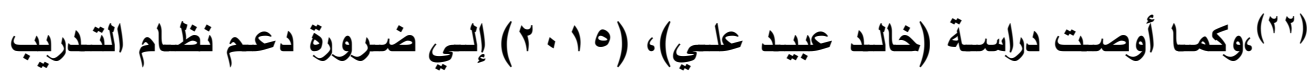
الإكتروني في جميع الجامعات المصرية بتوفير الأدوات والبرامج اللازمـة وتأهيل العاملين

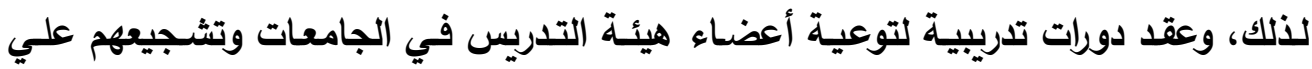

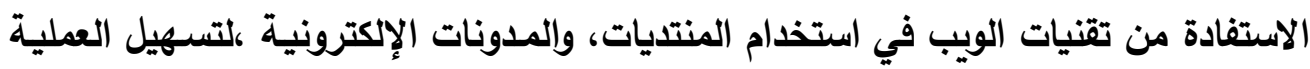

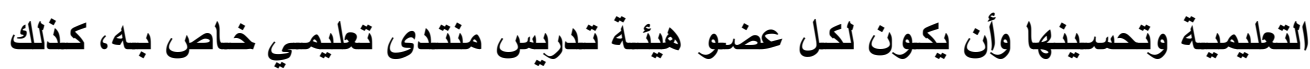

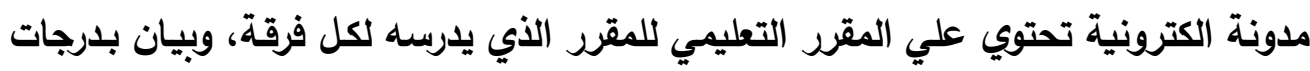

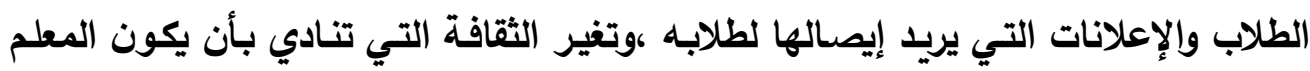
المصدر الوحيد للمعلومـة إلـي التعلم عن طريق المصـادر المفتوحة للتعلم، وجعل التعلم

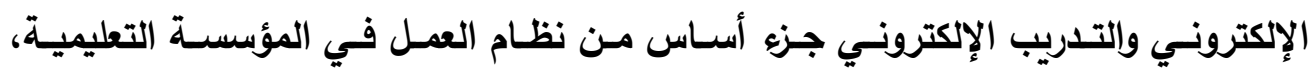
وتدريب الطلاب علي كيفية التواصل مع أعضاء هيئة التدريس عن طريق الأنترنت ،وبرامج

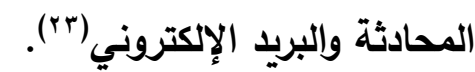

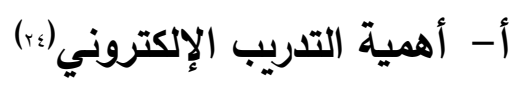

1. المتدرب هو المتحكم في العملية التعليمية أما المدرب فيكتفي بتوجيه المتدرب

$$
\text { r. المتدربون مشاركون في العملية التعليمية (تدرب إيجابي) }
$$

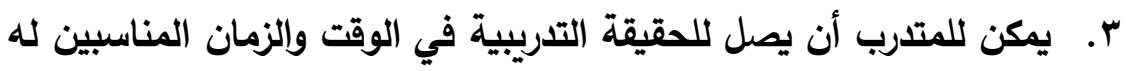


؛. . ينشي التدربب الإكتروني علاقة تفاعلية بين المتدبين والمدربين

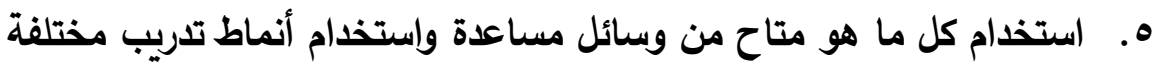
צ. تقليل تكلفة التدرب والسفر ورفع كفاءة المتدربين

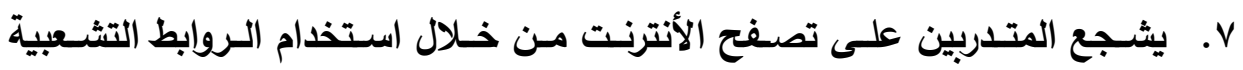
للوصول إلى معلومات إضافية حول موضوع الدرس ويطور من قدرة المتدرب في الإني

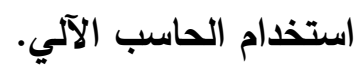

^. يثـجع المتـدرب على الاعتمـاد على النفس والوصسول إلى مرحلـة بنـاء المعرفـة ذاتيا، والاعتماد على النفس. 9 . . سمح للمدربين بتطوير المـادة التدريبية باستخدام المصادر الإكترونية والأنترنت والاحتفاظ بالسجلات. ـ 1 ـ الوقت والمنهج والتمارين تعتمد على مستوي ومهارات المتدرب وليس علي معدل

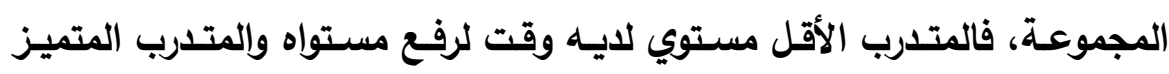

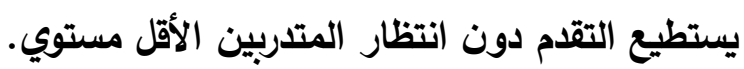

$$
\begin{aligned}
& \text { ب-أهداف التدربب الإكتروني } \\
& \text { ا ـ معرفة معني أو مفهوم التدريب الإلكتروني }
\end{aligned}
$$

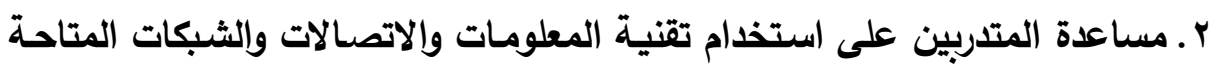

للتعلم الإكتروني لدراسة البرامج والمناهج والمقررات التدريبية ومراجعتها. r. تصميم برامج التدربب ومناهجه ومقرراته بطريقة رقمية الإنتية

ع ـ إعداد المتدربين للحياة في عصر الثقافة المعلوماتية هـ التغلب على مشكلات أساليب التدريب التقليدية 7. معرفة الأسس والمعايير التي يمكن من خلالها إجراء التعديلات لتطوير منظومـة

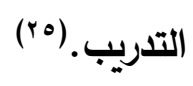

ثالثا: شبكات التواصل الاجتماعي شهر العالم في السنوات الأخيرة نوعا من التواصل الاجتماعي بين البثر في فضساء

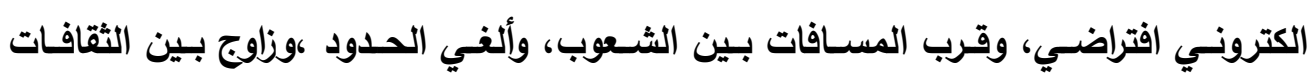

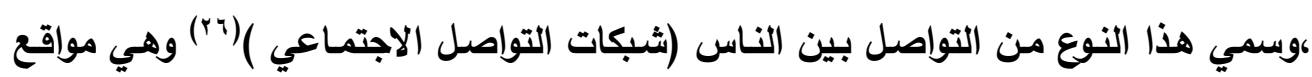


مبنية علي فكرة الثبكات الاجتماعية التقليدية حيث يمكن التواصل مـع أفراد جدد لا تعرفهم

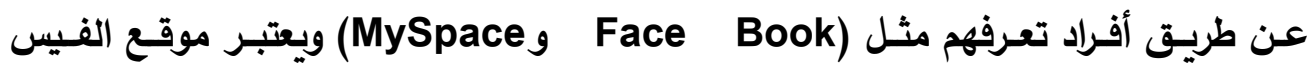

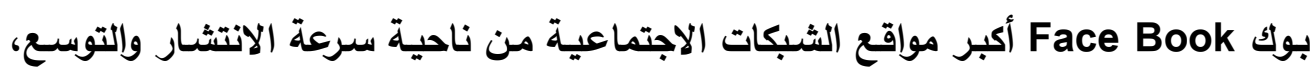

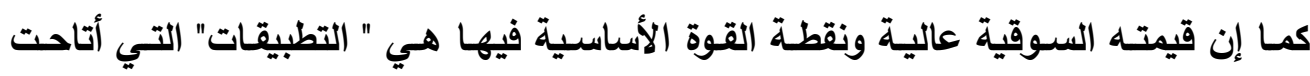

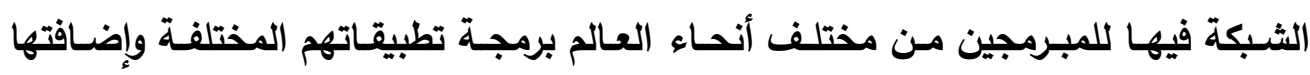
للموقع الأساسـي، كمـا أنها تذتصر الكثير من التطبيقـات وتسـاعد في الوصسول للملفـات

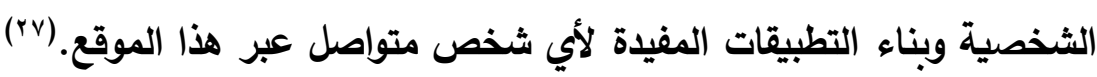
وتعد مواقع التواصل الاجتماعي الظاهرة الإعلامية الأبرز في عالمنـا اليوم، لكونها

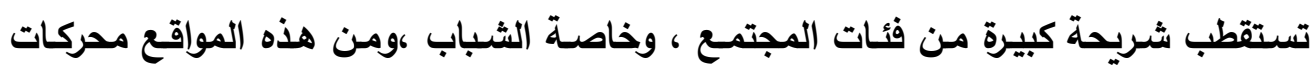

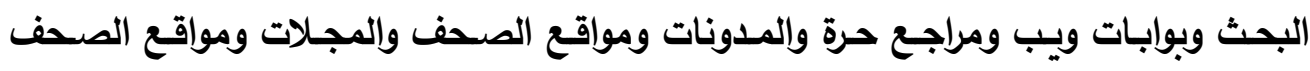

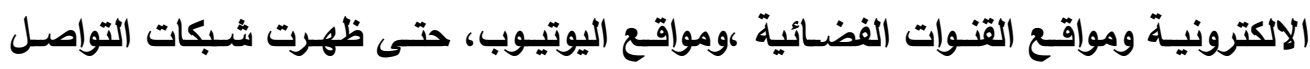

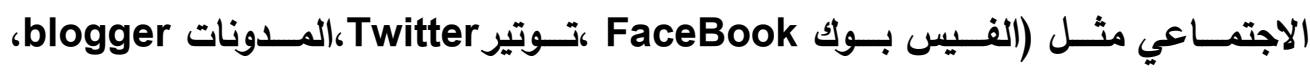
المنتديات forums،مـاي سبيس، لايـف بـوون، هـاي فـايف، واركت، تاجــ ، لينكد ان، يوتيوب وغيرها ) التي أتاح البعض منها مثل (الفيس بوك ) تبادل مقاطع الفيديو والصور لائري

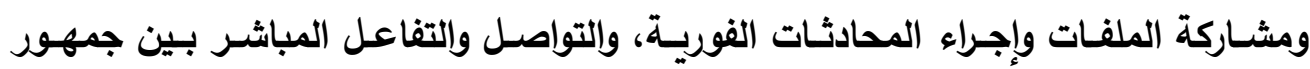

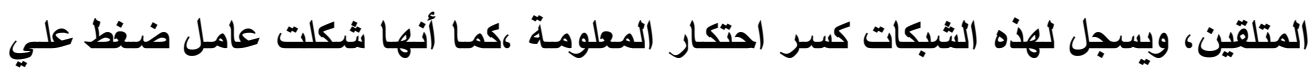

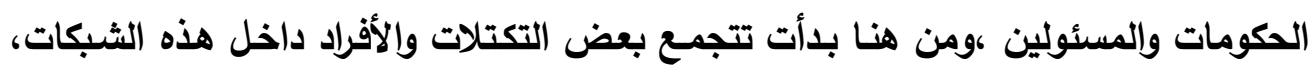

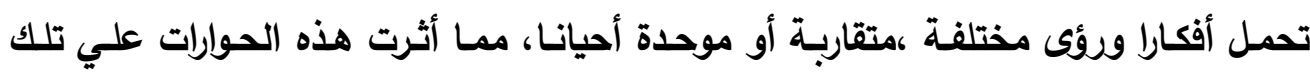
الشبكات وزادتها غني، وجعلت من الصعب جدا علي الرقابة الوصول إليها، أو السيطرة

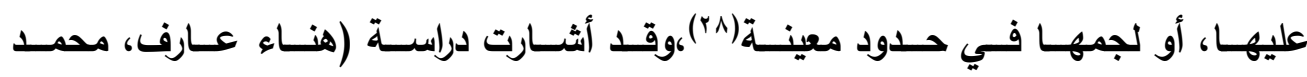

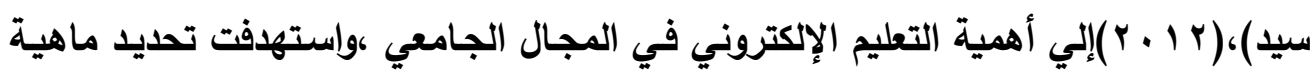

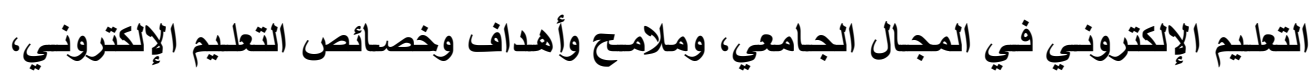

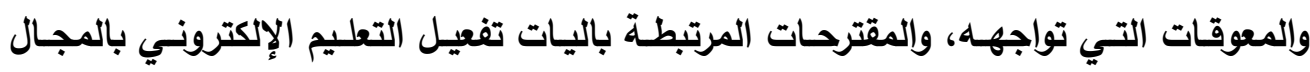

الجامعي في ضوء المتغيرات المحلية والعالمية (ra). ومن أهم شبكات التواصل الاجتماعي وأشهرها:

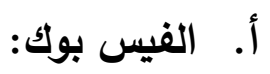


ويعد الفيس بوك Face Book أحد أهم المجتمعات الافتراضية أو التخيلية التي

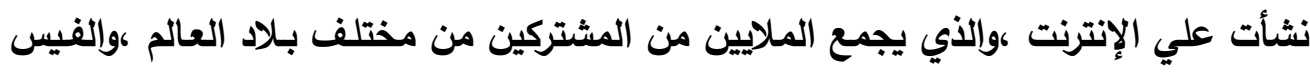

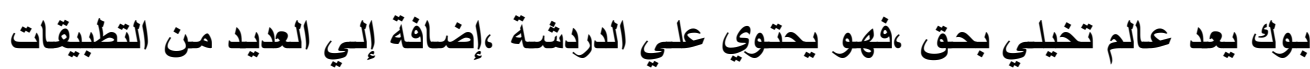
التي تتيح للفرد أن يعبر عن نفسه بشتى الطرق ،وان يتعرف علي حياة الآخرين ،والبيانات

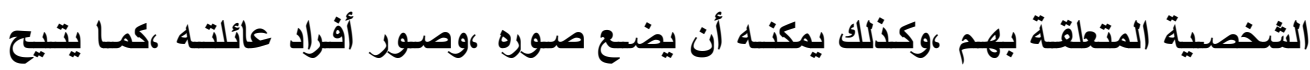
الفيس بوك الفرصة للاشتراك في العديد من المجموعات (جرو بات ) والتـي يجتمع أفرادها

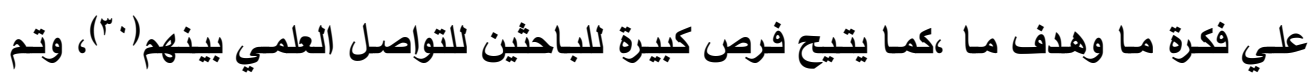
إنشاء الفيس بوك في ؛ فبراير ع . . ب علي يـ Mark Zuckerberg حين كان طالبا

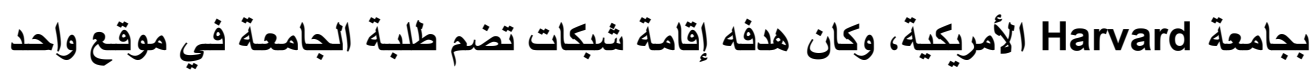

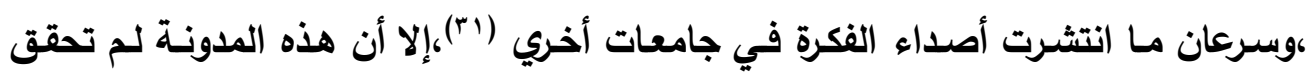

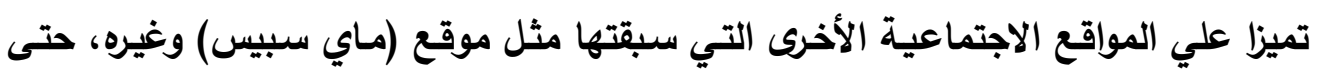

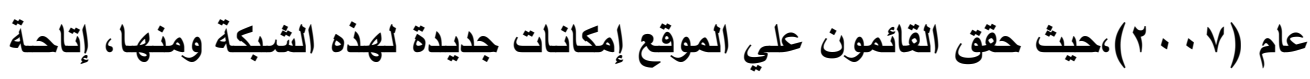

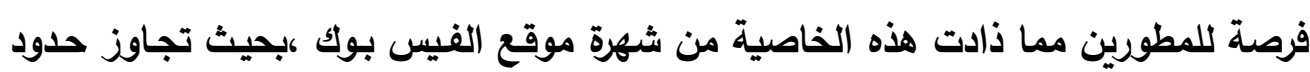

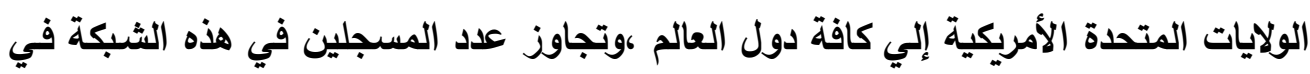

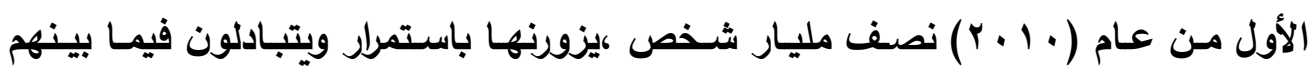

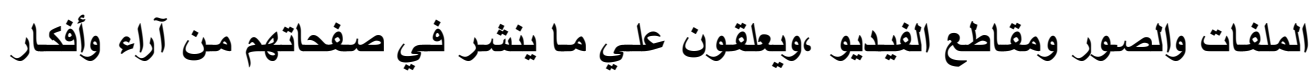

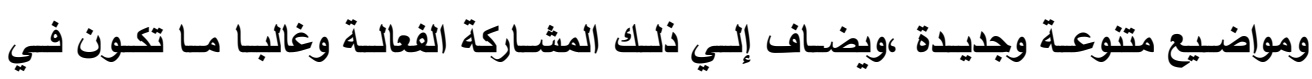
المحادثات وإلاردشات ، وتحتل الفيس بوك حاليا من حيث الثـهرة والإقبال المركز الثالث

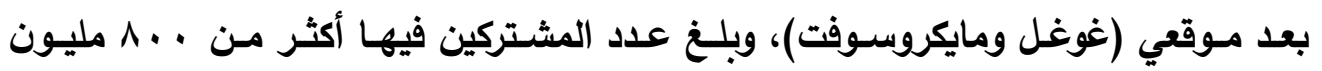

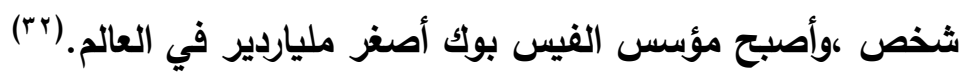
الآثار الإيجابية للفيس بوك:

يمكن للفيس بوك أن يحقق آثار إيجابية بالنسبة لمستخدميه، بل يمكن أن تمتد استخداماته لآثار إيجابية على المجتمع ولعل من أهمها:

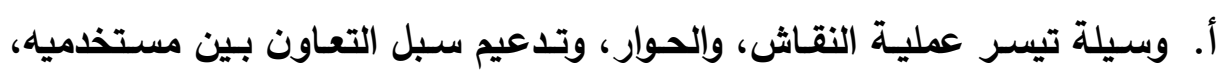

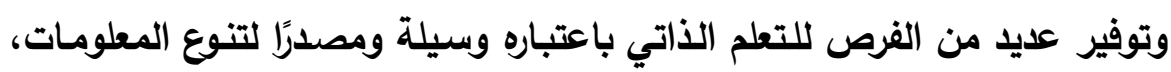
وتبادل المعرفة مع الآخرين. 
ب. وسيلة اتصال، بل تواصل بين مستخدميه ذات طابع دولي عابر للحدود السياسية

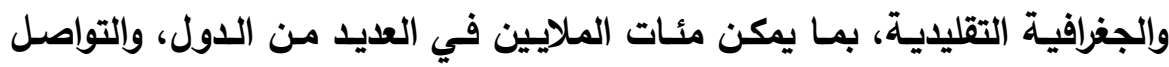
الدائم وتناقل المعلومـات والبيانات في ذات اللحظة متجاوزين كل حواجز المكان والزمان.

ج. يتيح التواصل بين الأهل والأصدقاء وتبادل الأخبار في مجالات الدراسـة أو العمل بين المشاركين، بل وتكوين صداقات جديدة. د. وسيلة للتعبير عن الرأي بحرية، والتواصل بين مجموعات كبيرة من المستخدمين

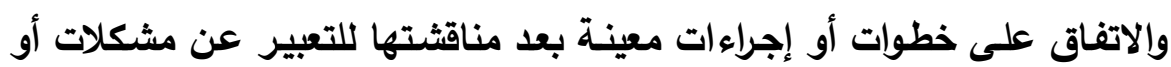
قضايا المستخدمين. هـ. يعد نافذة يطل منها المواطنـون على العـالم الخـارجي ويستطيعون مـن خلالـه

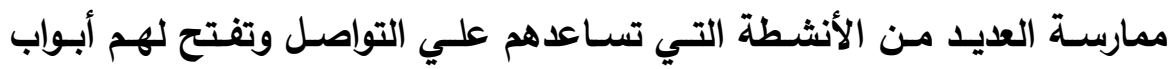
تمكنهم من إطلاق إبداعاتهم ومشاريعهم التي تحقق أهدافهم وتسـاعد في تنمية لتهية

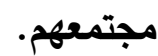

و. يمكن مـن خـلال اسـتخدامه التبـادل الثقــافي، والعلمي، ومختـف الخبـرات بـين المشتركين والتعرف علـي عـادات وتقاليد مجتمـع جديـ ،والانفتـاح علـي العـالم

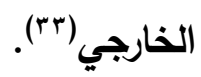
ب. بوتير: هو إحدى شبكات التواصل الاجتماعي ،التي انتشرت في السنوات الأخيرة ،ولعبت

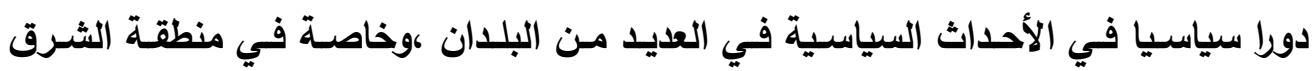

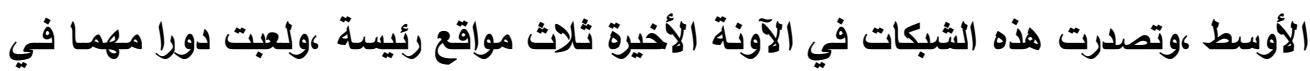

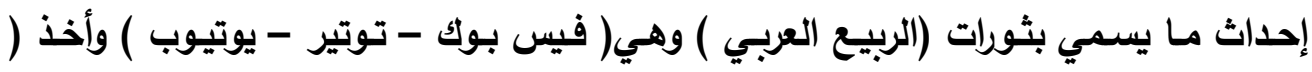

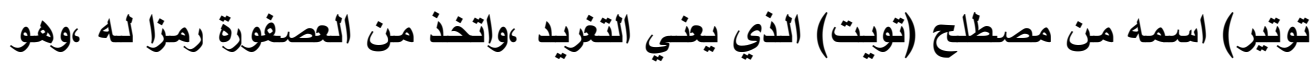

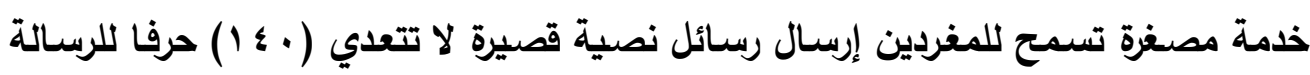
الواحدة ،ويجوز للمرو أن يسميها نصا موجزا مكثفا لتفاصيل كثيرة، ويوفر توتير لمستخدميه

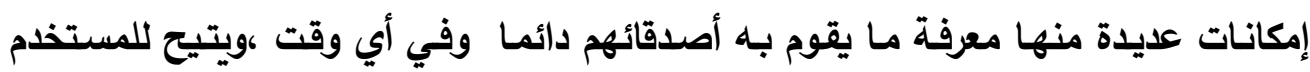

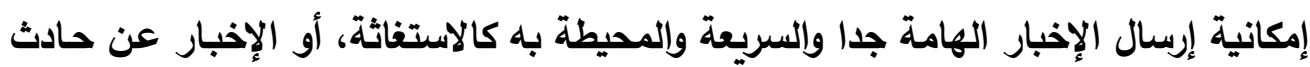


ج. خصـائص شـبكات التواصـل الاجتمـاعي وأبرز الخدمات التـي تقدمها الشـبكات الاجتماعية:(ro)

1- الملفات الثخصية أو صفحات الويب: وهي ملفات تمكن الفرد من خلالها كتابة

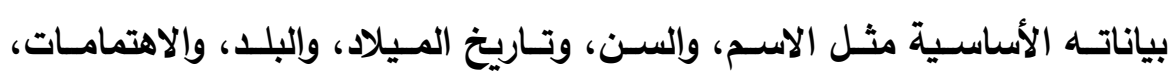

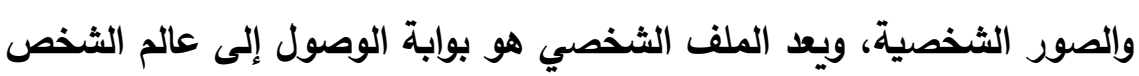

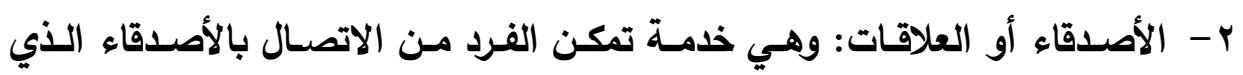

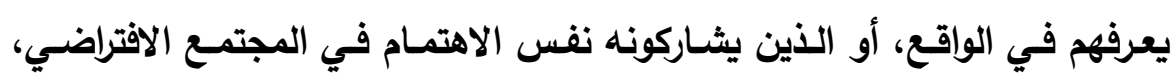

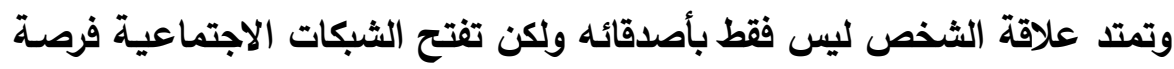
للتعارف مع أصدقاء الأصدقاء بعد موافقة الطرفين.

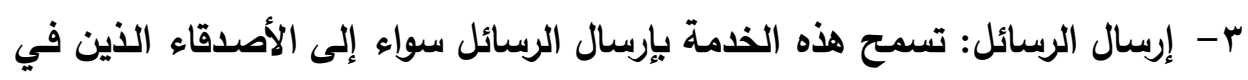
قائمة الثخص، أو غير الموجودين في القائمة.

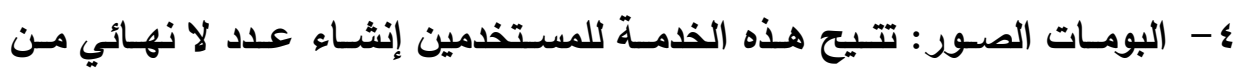

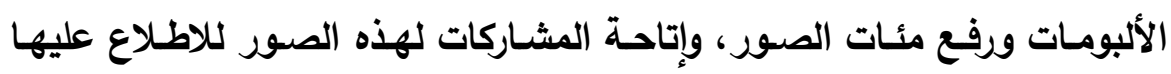
وتحويلها أيضا. ه- المجموعات: تتيح الثبكات الاجتماعية فرص تكوين مجموعات الاهتمام، حيث

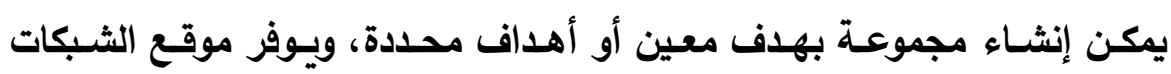

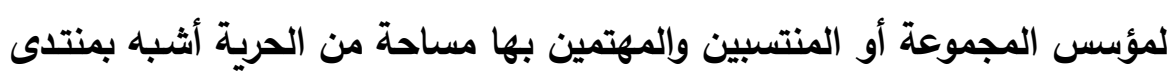
حوار مصغر ، كما تتيح فرصة التنسيق بين الأعضاء في الاجتماعات من خلال

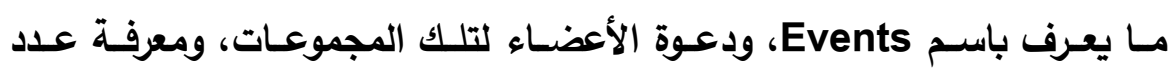
الحاضرين وإعداد غير الحاضرين. 4- الصفحات : ابتدعت هذه الفكرة الفيس بوك ،وتم استخدمها تجاريـا بطريقة فعالـة

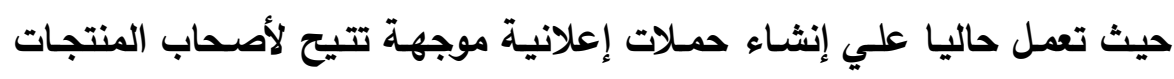

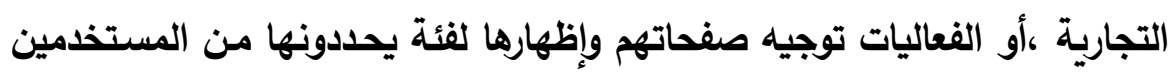

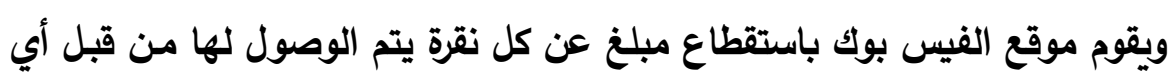

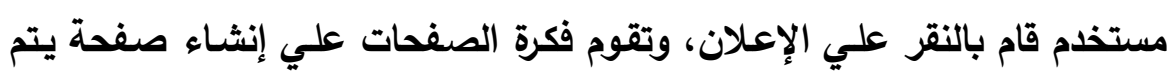

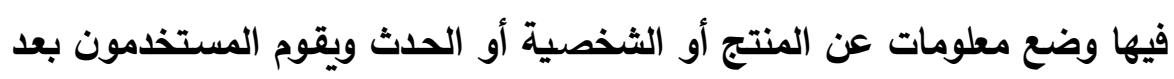


ذلك بتصفح تلك الصفحات عن طريق تقسيمات محددة ثم وإذا حدث اهتمامـا بتلك الصفحة يقومون بإضافتها إلي ملفهم الثخصي.

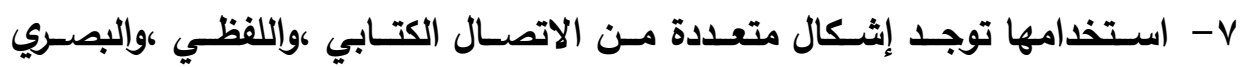

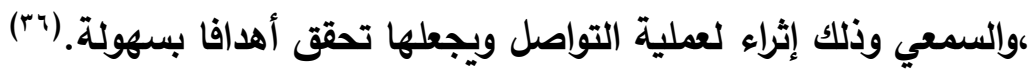
د. ـ وظائف شبكات التواصل الاجتماعي:

1 ا تبادل المعلومات والأفكار والآراء r. الصحبة وتكوين صداقات جديدة. r. التعليم والتطوير المهني.

ع ـ شغل وقت الفراغ (rv)

هـ هلبيات شبكات التواصل الاجتماعي:(^)

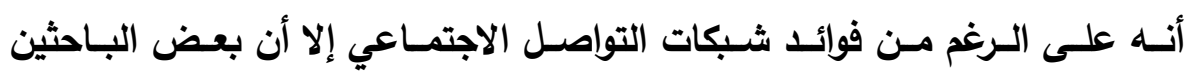
والخبراء في هذه الشبكات يرون أن ثمة سلبيات يمكن إنجازها في النقاط التالية:

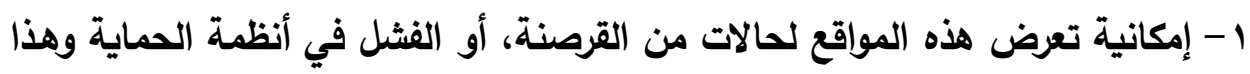

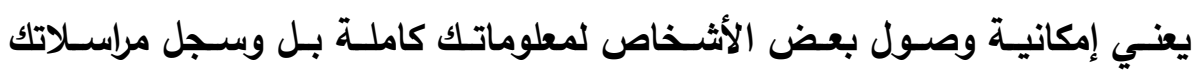
الخاصة.

r - الإدمان على هذه المواقع حيث تخلق شبكات التواصل جوا من المتعة والإثارة التي

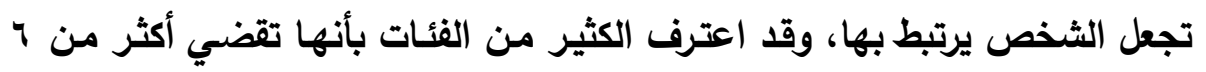

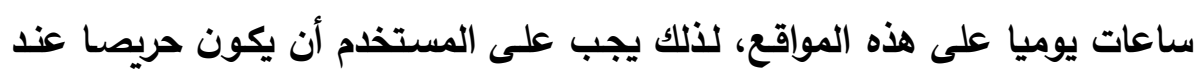
استخدام هذه الثبكات من الوقوع في طية الإدمان.

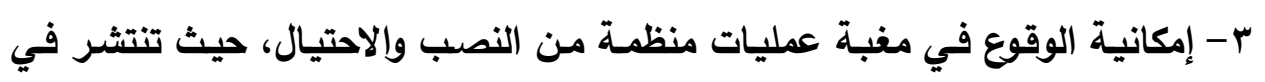

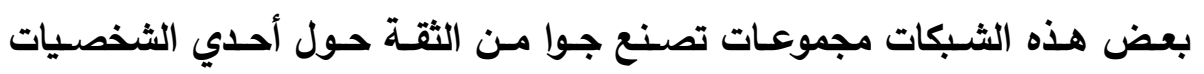

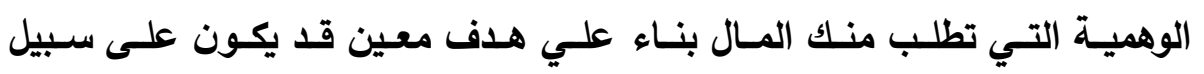
الاستدانة، أو على سبيل الاستثمار.

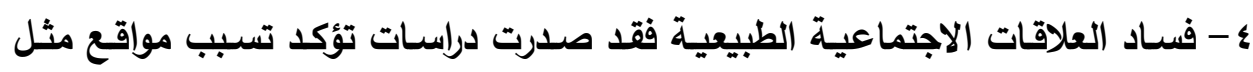
الفيس بوك، وماي سبيس بنسب تفوق .%من حالات الطلاق.

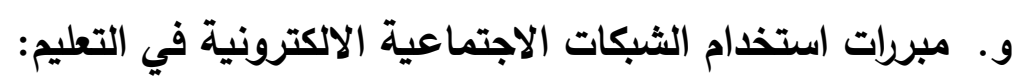


أصبحت الثبكة الاجتماعية الاكترونية في العصر الحديث ضرورة تربويـة لا يمكن

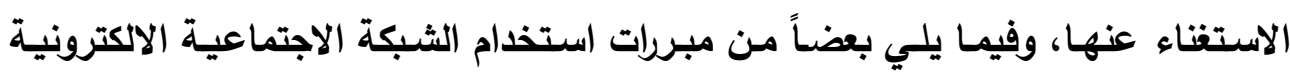

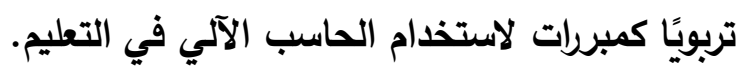

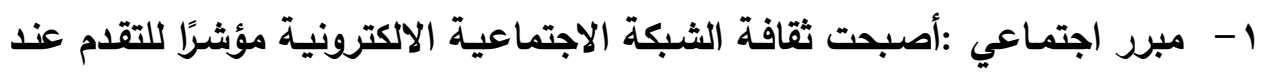

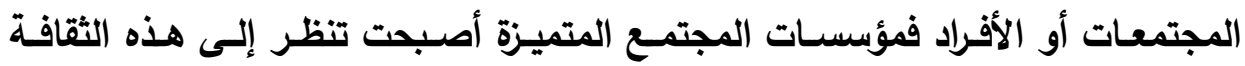

\section{كمؤشر للكفاءة.}

r- مبرر مهني :الشبكة الاجتماعية الاكترونية تمنح العاملين قدرات ومهارات تفيدهم في إتقان أعمالهم المختلفة، وتوفر الجها والوقت والألماله r- مبرر إبداعي: إن يحفز المستخدمين للإبداع بما يوفره لهم من نماذج وآليات تنفيذ ولهمئ

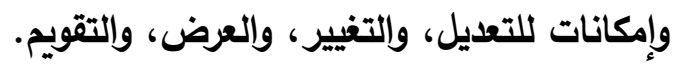

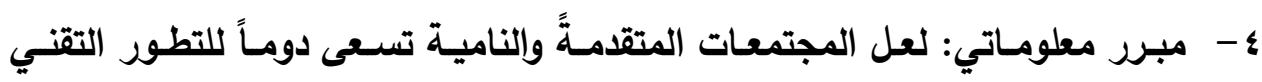
لينعكس ذلك عليها اقتصـاديا وسياسيا واجتماعيا، والثـبكة الاجتماعيـة الاكترونيـة تأتي في قمة التطور التقني. ه- مبرر الاحتياجـات الخاصـة: ذوي الاحتياجـات الخاصـة وخاصـة الموهوبون يجدون في الثبكة الاجتماعية الاكترونية ما يتناسب مع احتياجاتهم.

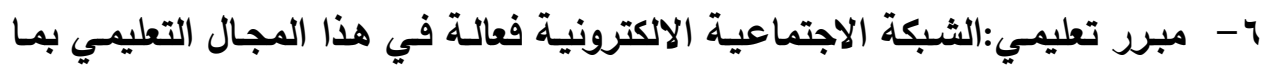

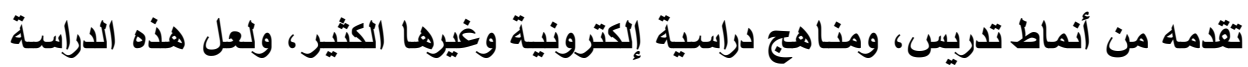
تتماشى مع هذا السياق 39(). - V - التفاعل: تعد مـن المبررات المهمـة عند تطبيق التعليم عبر الشبكات، فالطالب

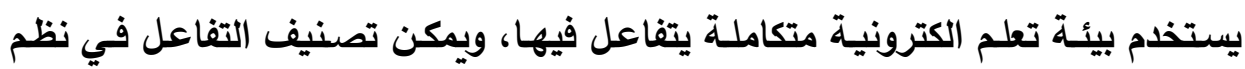

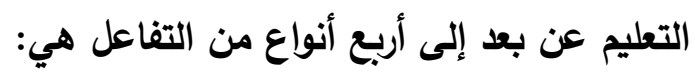

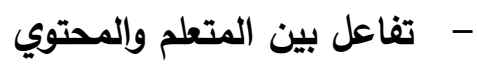
- - تفاعل بين المعلم وإلمتعلم - تفاعل بين المتعلم وزميله

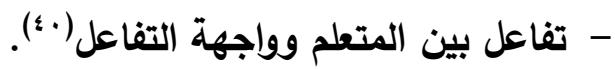
ز. فوائد استخدام الثبكات الاجتماعية في عملية التعليم والتعلم : 
التواصل السريع يتواصل المعلمون عبر شبكة البريد الالكتروني مـع بعضهم ببعض

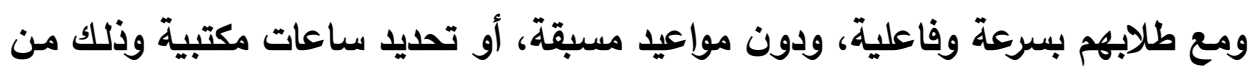

خلال:

1 - التعرف على أحدث الإصدارات في مجال المـادة التي يقوم بتدريسها، وتوفير مـا

$$
\text { يحتاجه من أبحاث، ومقالات، واختبارات، وطرق تدريس. }
$$

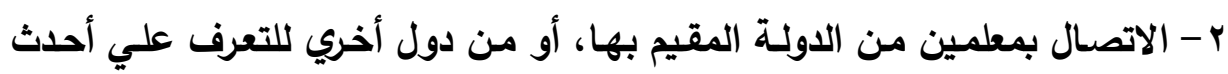

$$
\text { الاتجاهات العلمية في مجال التدريس. }
$$

r- تكوين جماعات ذات اهتمام تعليمي مشترك يمكنهم تبادل الخبرات فيما بينهم. ع - الحصول على برامج، وملفات، وفيديو، ووسائل تعليمية عبر المنتديات.

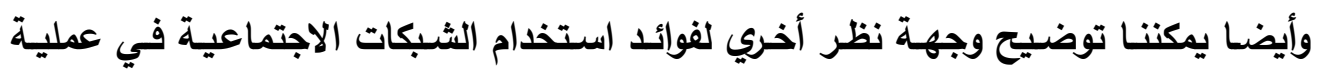
التعليم والتعلم. - - سـهولة وسـرية وضـمان انتقال الرسـائل يستطيع أي فرد عن طريق خدمـة البريـا

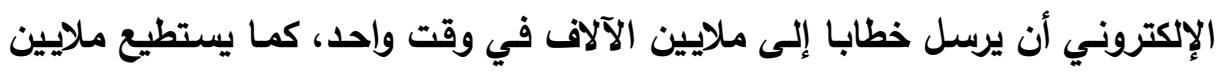

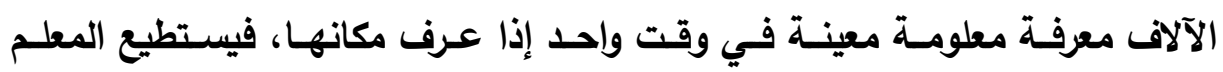
الاتصـال بطلبتهـ، وإرسـال معلومـات لمجموعـة مـن المعلمين أو الطلبـة المثـتركين بقائمة تعليمية. r- العالميـة عبر الثـبكات الاجتماعيـة الاكترونيـة يمكن الوصـول لأكبر عدد مـن المتابعين في أي مكان في العالم، والخروج من الإطار المحلي إلى العالمي.

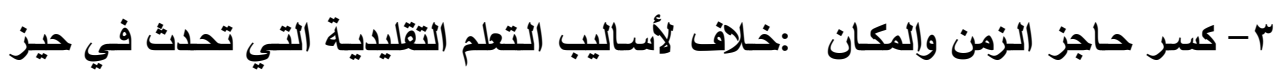

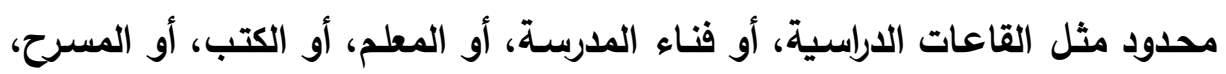

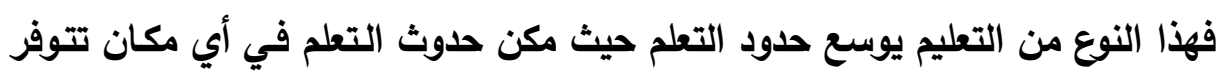

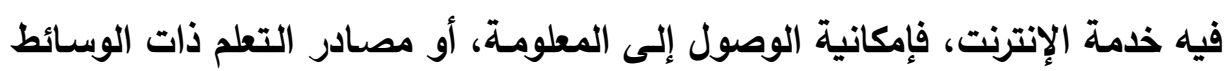
المتعددة المتاحة بسهولة ويسر، بغض النظر عن الموقع بما يسمح للمتعلم مواصلة التعلم. ع - انخفاض التكلفة إثـارة (Khan) دروس الثبكات الاجتماعية الاككترونية ذات كلفة

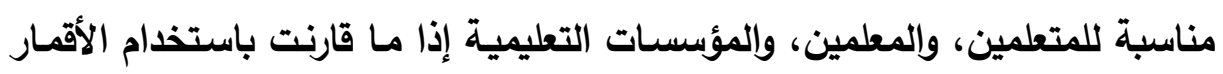

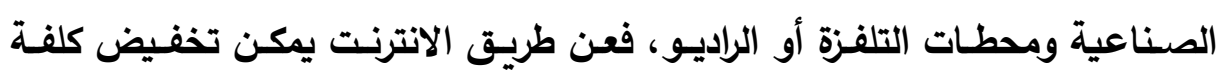




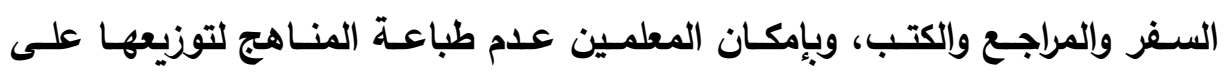

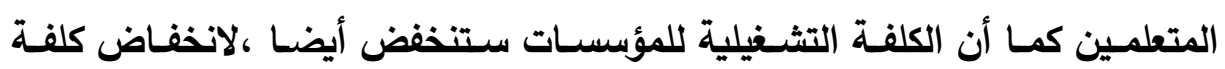
الصيانة والتسهيلات المادية. ه- الكفاءة التعليمية: نظرا لاستخدام بعض الثبكات الاجتماعية الاكترونية العديد من

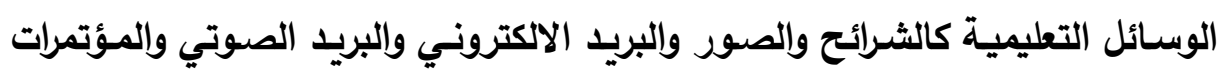

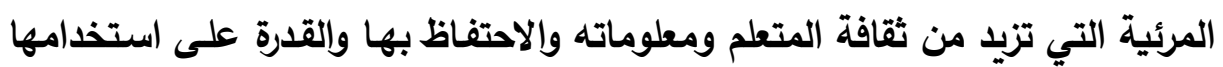
في مواقع الحياة العملية والقدرة على التواصل مـع الآخرين، بناء على ذلك أصبح للإنترنت أهمية كبيرة في تدريس المناهج وتحصيلها من جانب المتعلم

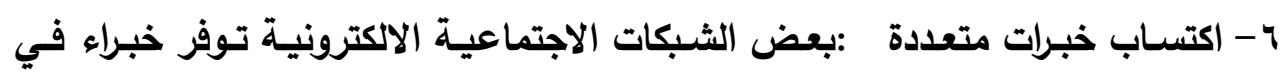

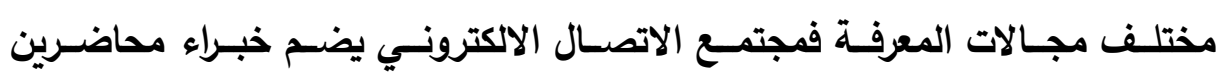
وضيوف، وهذا يوفر لاثك ميزة تنوع الرؤى العلمية، وتنوع مصادر المعرفة والخبرة.

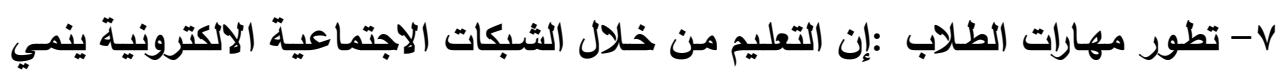

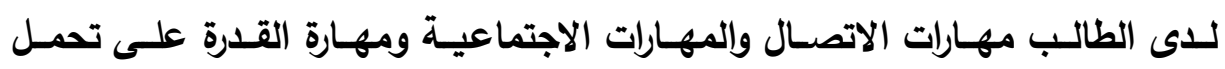
المسئولية ،والاحتكاك بالآخرين، ومشاركتهم خبراتهم، ومهارة التفكير الناقد، والقدرة

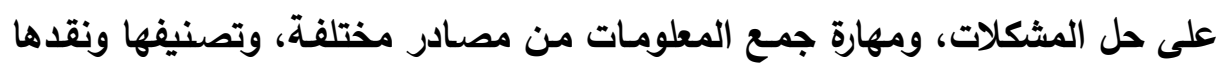

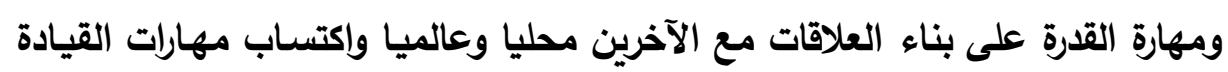
وبناء الفريق (1). 1- تعزيز البحث العلمي :مـن خـلال اطلاع الطلاب على الكتب والمجـلات واللدوريات

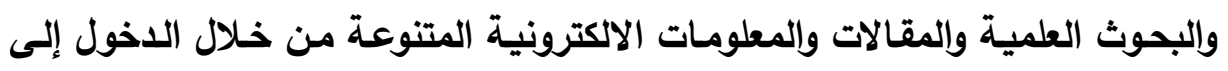

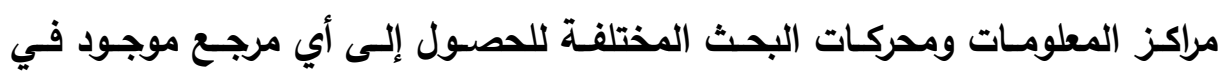

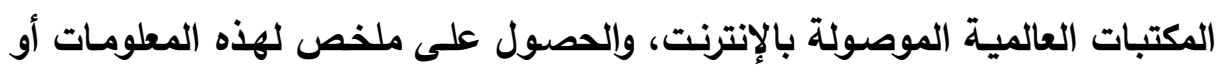
مقالات كاملة يمكن تخزينها (r). ح. المعايير التي لابد أن يلتزم بها أعضاء هيئة التدريس والطلاب أثناء التواصل التعليمي عن طريق شبكات التواصل الاجتماعي: 1- التعرف على الأهداف المطلوبة من التواصل التعليمي من خلال الثبكة التعليمية. 
r - شـرح السياسيات والقوانين الخاصـة باستخدام شبكات التواصل الاجتمـاعي في العملية التعليمية. r- توضيح السلوكيات المطلوب التعامل بها من خـلال شبكات التواصل الاجتمـاعي وضرورة شعور الطلاب بالملكية.

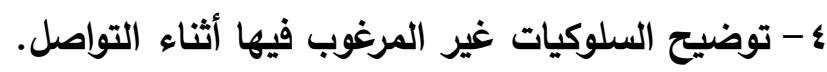

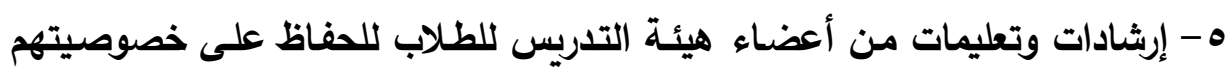
الشخصية צ- لابــ أن يكون مجمل النشـاط الذي يمـارس من خـلال الصفحة التعليمية خـاص

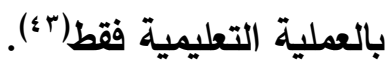
تعتني طريقة العمل مع الجماعات بتزويد الأفراد بمهارات التعامل مـع مراكز المعلومـات واستخدام شبكة المعلومات والإنترنت والمستجدات التي تطرأ علي حياة المجتمعات والتي لتئي تتطلب أفراداً قادرين علي التعامل في مجتمع المعلومات ولا يشعرون فيها بالاغتراب (؛ ؛). ط. خدمة الجماعة والتخفيف من مشكلة استخدام الشباب السلبي لمواقع التواصل

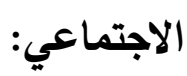
الخدمـة الاجتماعيـة كمهنـة تمتـــ لأكثر من مائسة عام تغيرت من حيث مجالاتها وعمق ممارساتها فعلي الرغم من الوظائف المتنوعة، والطرق العديدة المتغيرة في الخدمـة ماكسة

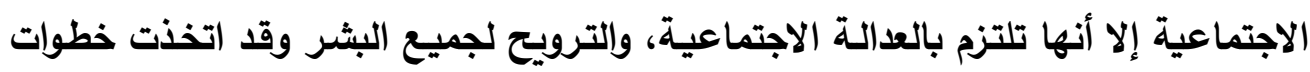

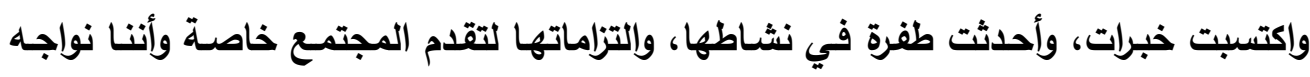

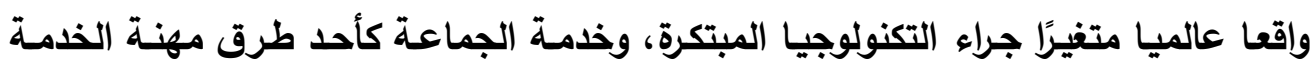

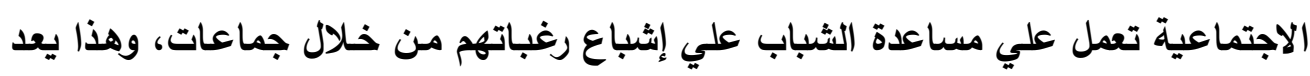

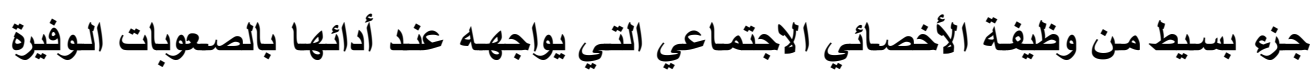

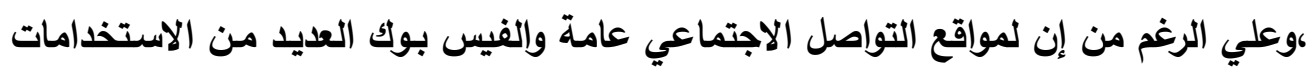

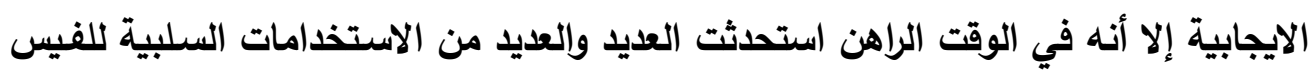

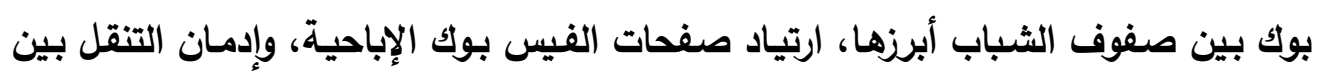

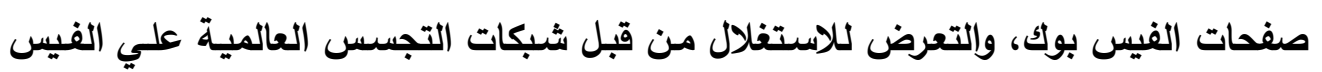

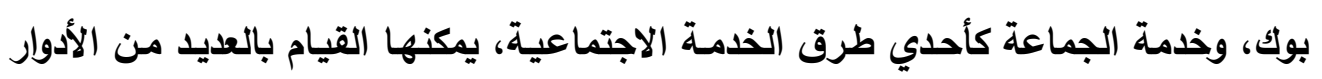


من خـلال أخصـائي العمل مـع الجماعات للتخفيف من مشكلة الاستخدام السلبي لمواقع

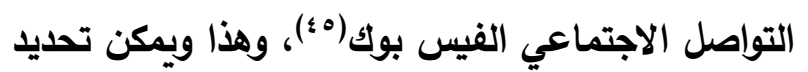

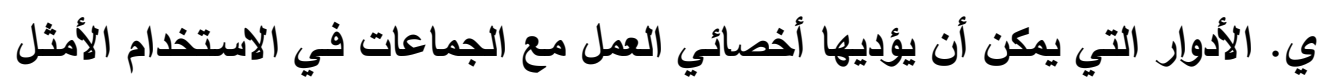
لشبكات التواصل الاجتماعي

ا ـ مساعدة الطلاب على تحديد أهداف استخدامهم للفيس بدقة، ووضع حدود لها.

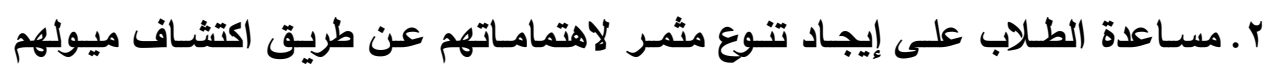

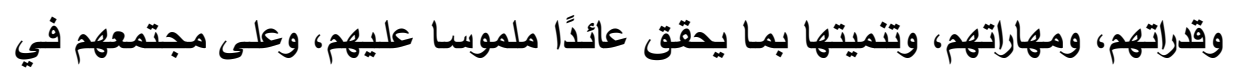
آن واحد.

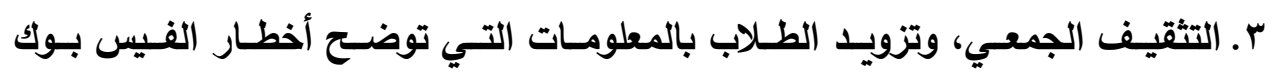

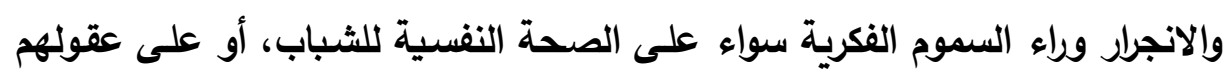
وآرائهم، أو على محيطهم الاجتماعي وضمن علاقاتهم الاجتماعية الطبيعية. ـ ـ مساعدة الطلاب على استخدام الفيس بوك في الجانب التعليمي من خلال الآتي: - - أيجاد مصادر معلومات خاصة بالطالب.

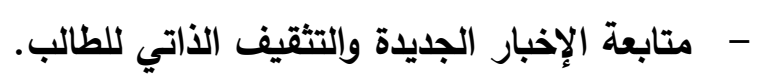
- - مساعدة الطلاب الترويج لمؤسستهم. - مئل

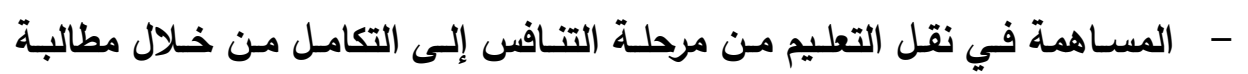

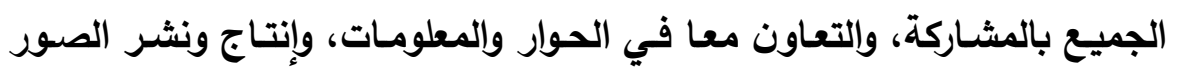
ومقاطع الفيديو والروابط وغيرها في مجموعة أو صفحة المادة في الفيس بوكت ولك.

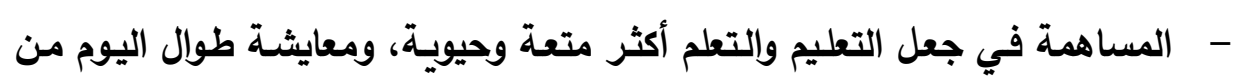

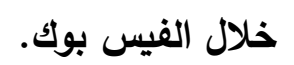
- التشـبع علـي اسـتخدام التقنيـة والانترنـت وإلثـبكات الاجتماعيـة الفـيس بـوك تحديدا في التعليم والتعلم (" ؛). ك. أهمية التواصل الإكتروني:

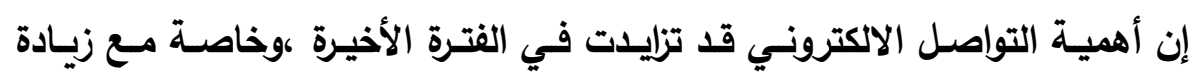

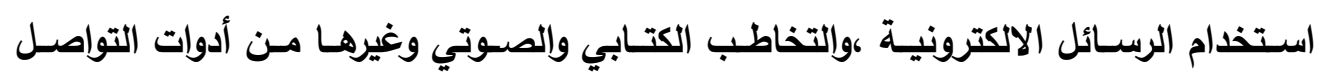

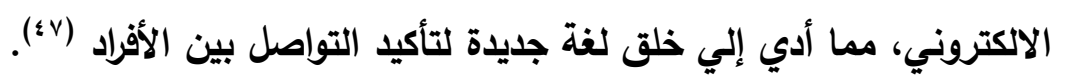


ل. أهداف جماعات التواصل (الاككتروني) التكنولوجي:

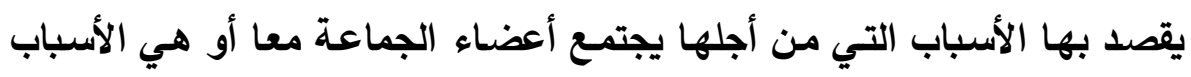

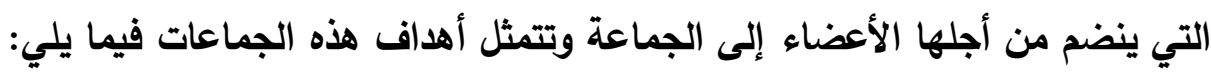

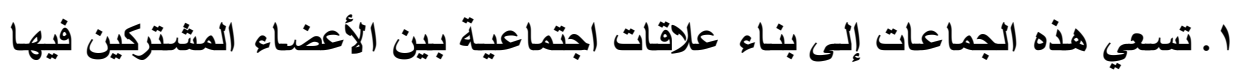

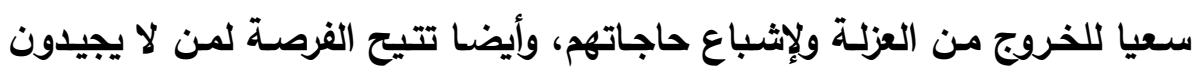

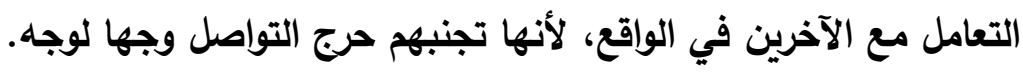

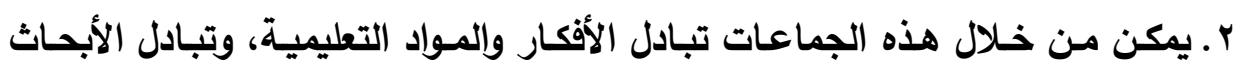
والرسائل العلمية بين الطلاب.

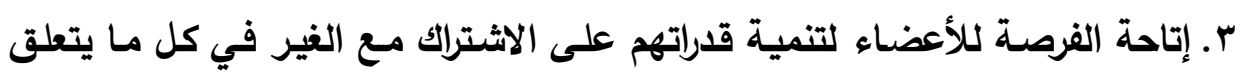
بهم من أمور في أثناء حياتهم الجماعية. ؛ . يمكن من خلال جماعات التواصل التكنولوجي تبادل الكتابات الأدبية ،وتبادل الآلهاء حولها (48). ه. نشر التقنية في المجتمع وإعطاء مفهوم واسـع للاتصـال المستمر، وتطوير فلسفة ونظم الاتصال التقليدي.

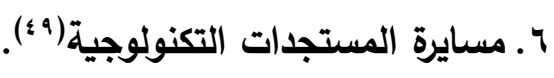
نتائج الدراسة:

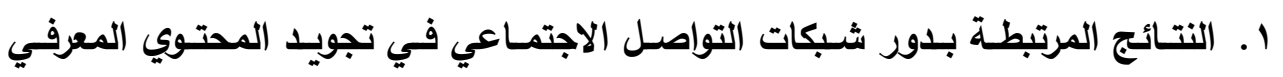

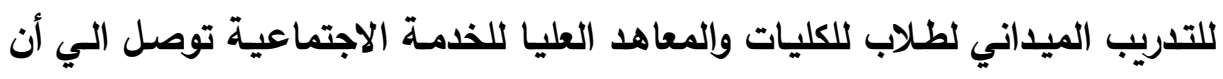
شبكات التواصل الاجتماعي تساعد في معرفة مواعيد التدريب الميداني بوسط وزنسي

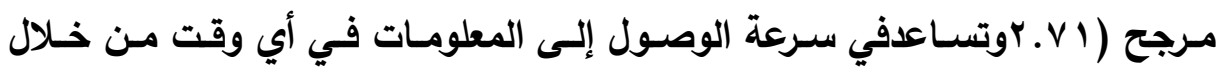
شبكات التواصل الاجتماعي بوسط وزني مرجح (^.^. (Y).

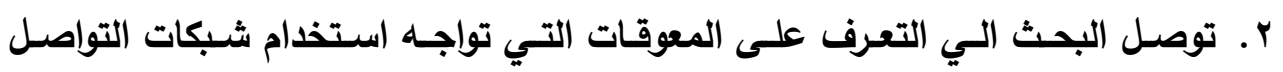
الاجتماعي في تجويد برامج التدريب الميداني: جاء في الترتيب الأول انتشار السلبية

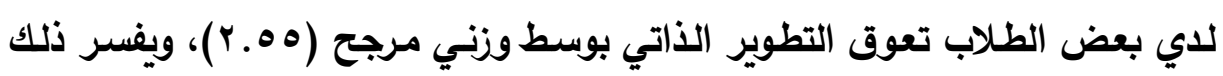

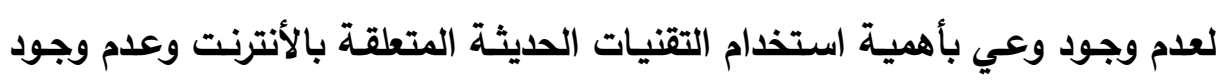
حوافز تشجيعه ورغبة في التطوير. 
r. وتوصل البحث أيضـا الي آليات تفعيل دور شبكات التواصل الاجتمـاعي في تجويـ التدريب الميداني لطلاب الخدمة الاجتماعية: جاء في الترتيب الأول يمكن استخدام الثبكات الاجتماعية الإكترونية في التطوير من مهارة التسجيل بوسط وزني مرئهي

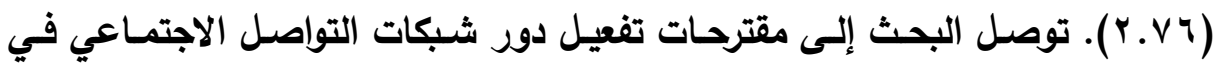

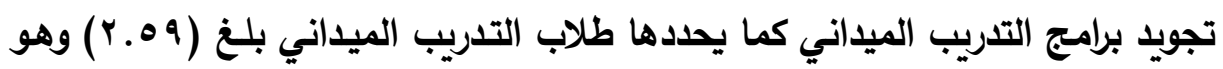
معدل مرتفع. 
(1) رضا مسعد السعيد ، ناصر السيد عبد الحميد (· • ب): توكيد الجودة في مناهج التعليم ،

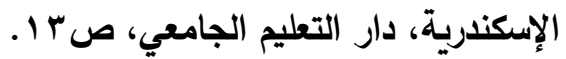

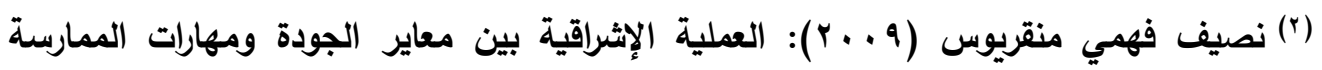

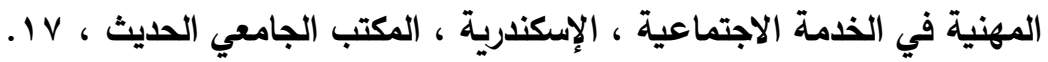

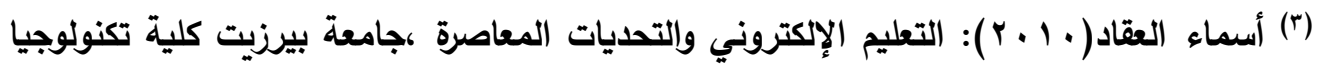
المعلومات قسم هندسة أنظمة الحاسوب.

http://www.aun.edu.eg/conferences/27_9_2009/ConferenceCD_files/Pape rs/35.doc

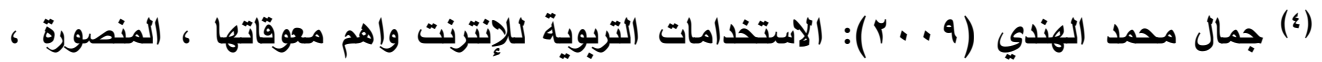

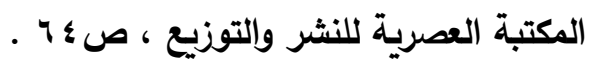

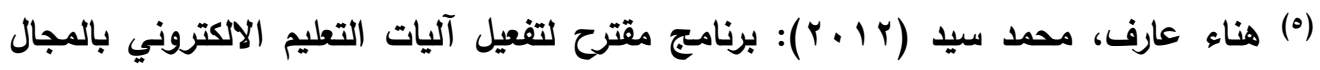
الجامعي من منظور طريقة خدمة جماعة"، بحث منشور في المؤتمر العلمي الخامس والعشرين للخدمة الاجتماعية، كلية الخدمة الاجتماعية ،جامعة حلوان، الجزء الأول.

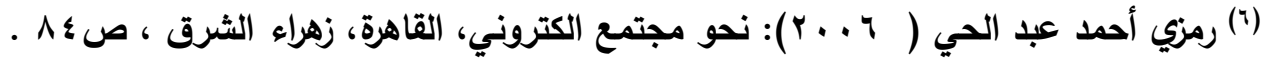

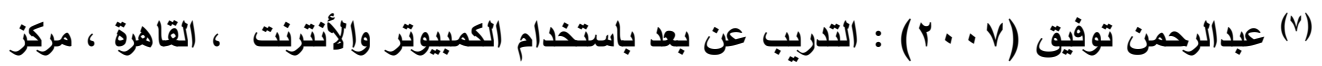

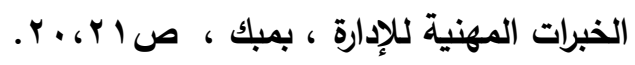

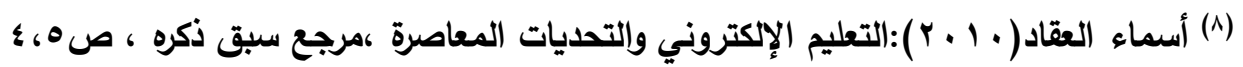

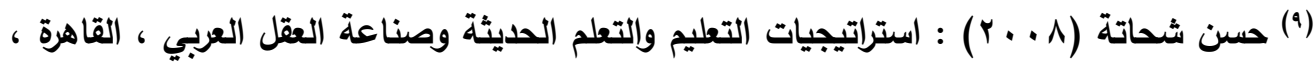

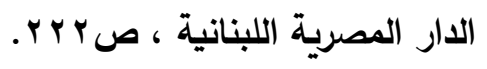

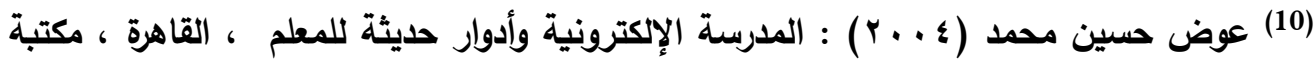

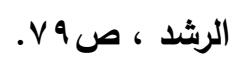

(11) مني هادي صالح (r 1 + ץ): دراسة إمكانية تطبيق بيئة تعليم افتراضية ،بحث منشور في مجلة

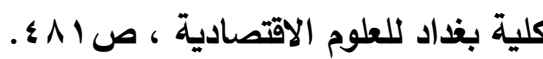

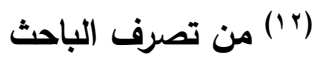

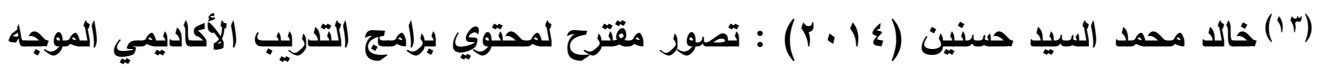

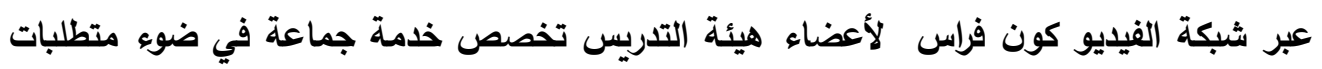


مجتمع المعرفة ، بحث منشور في المؤتمر العلمي السابع والعشرين ،الجزء الثالث ، كلية الخدمة

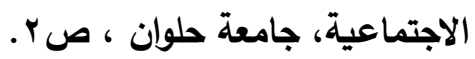

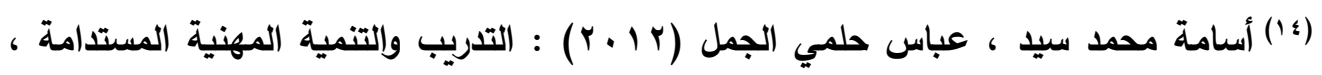

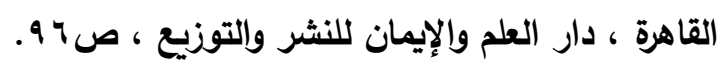

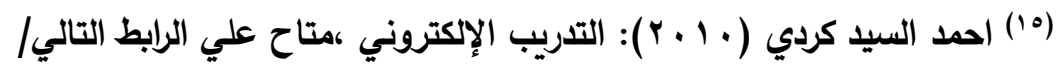
Httb://kenanaonline.com/users/ahmedkordy/topics/68625/posts/127750.

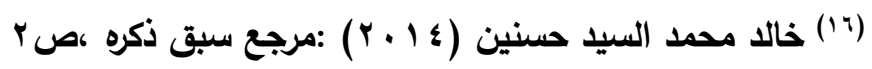

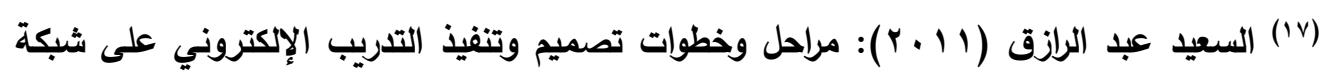

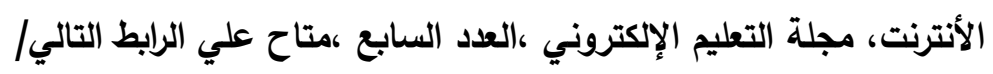
http://emag.mans.edu.eg/index.php?pa...sk=show\&id=224

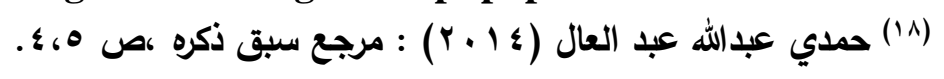

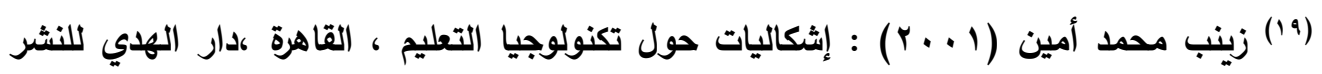

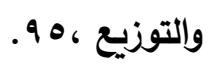

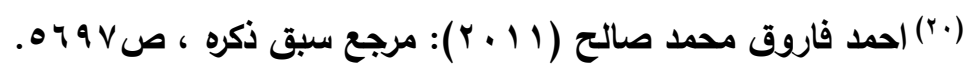

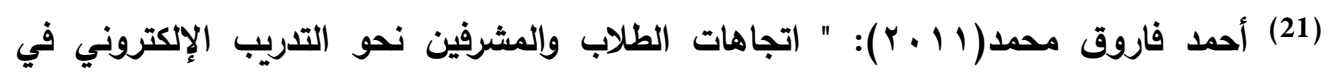

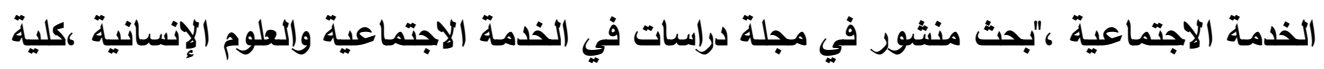

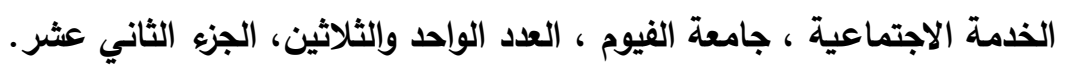

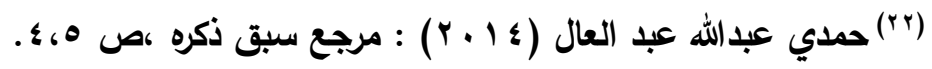

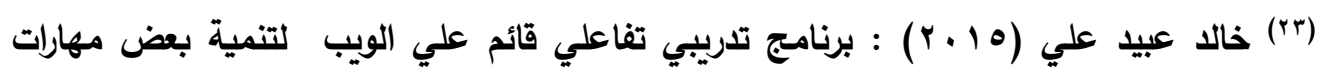

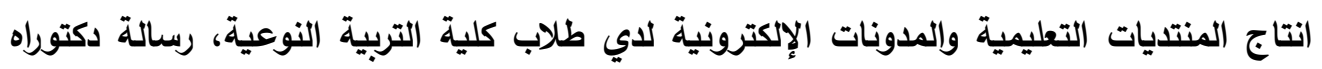

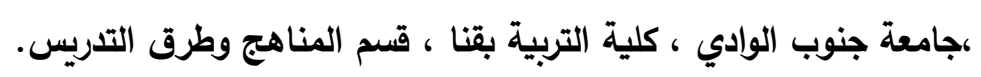

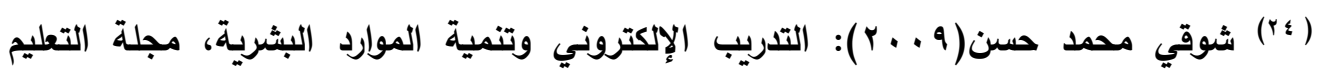

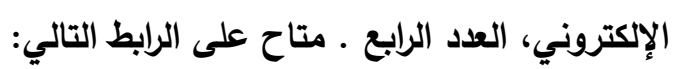
http://emag.mans.edu.eg/index.php?sessionid

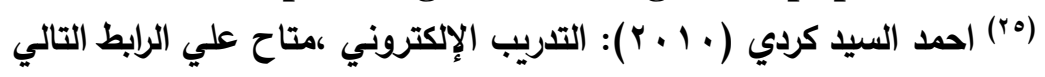

Httb://kenanaonline.com/users/ahmedkordy/topics/68625/posts/127750

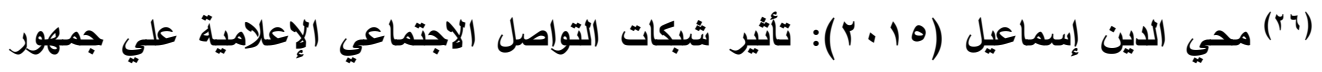

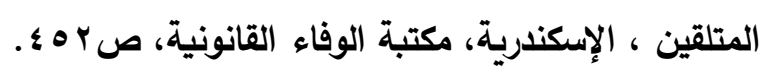




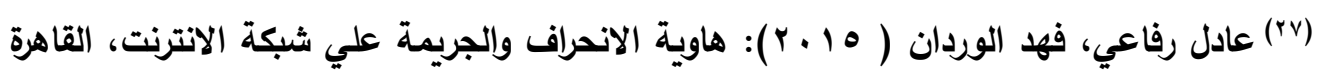

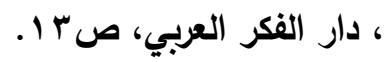

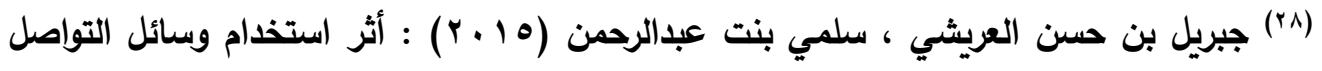

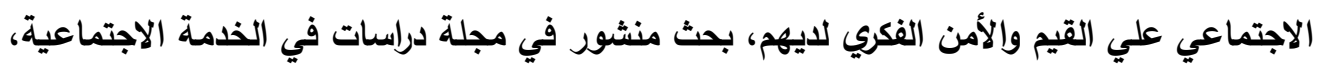

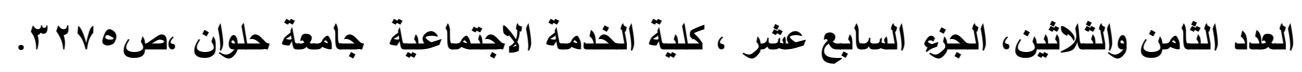

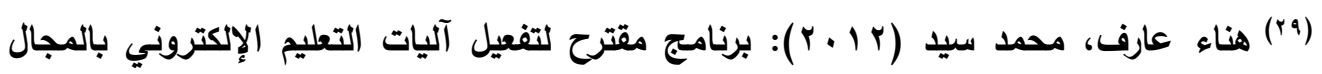

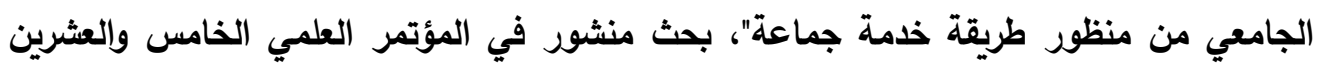
للخدمة الاجتماعية، كلية الخدمة الاجتماعية ،جامعة حلوان، الجزء الأول.

(30) Ellison "The Benefits office Book" Friends "Social Capital College Students', N., stein Field, C. \& Lampe, C. ( 2007). Use of Online Social Network Sites. Journal of Computer Mediated Communication. Vol. 12. Issue 4.

("r) محمد السيد حلاوة ، رجاء عبد العاطي (11 +r): العلاقات الاجتماعية للشباب بين دردشة

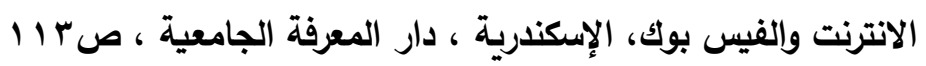

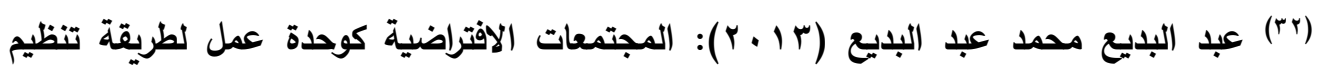
المجتمع ودورها في نثر ثقافة المواطنة بين الثباب ، رسالة ماجستير ، كلية الخدمة الاجتماعية

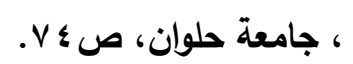

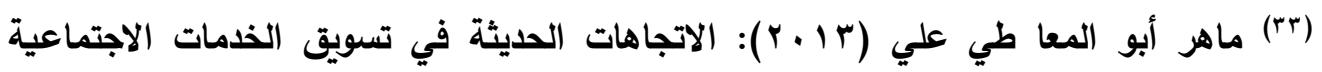

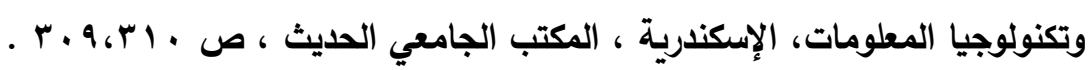

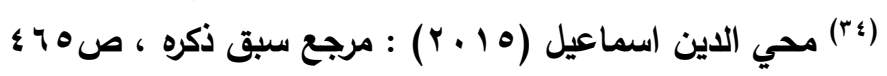

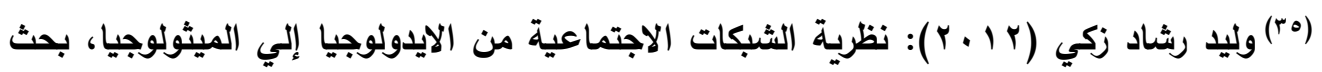

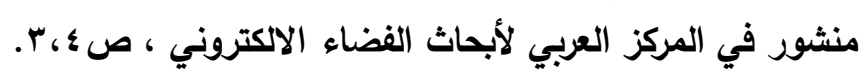
("ч) Mazman, S. G. \& kocakus- luel, Y. (2009). "the Usage of Social Networks in Educational Context". International Journal of Human and Social Sciences. Vol. 4. No. 12. pp. 849-853.

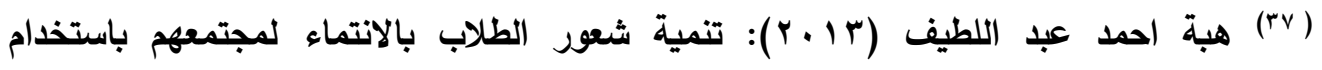

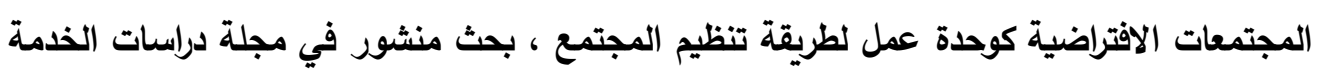

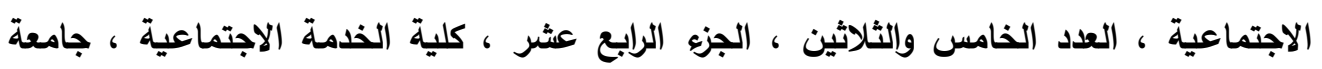




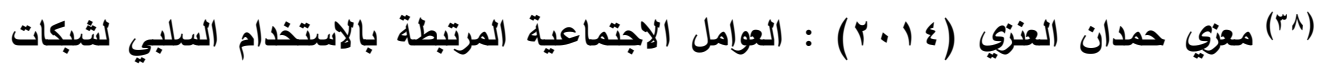

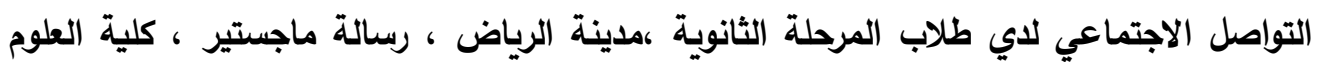

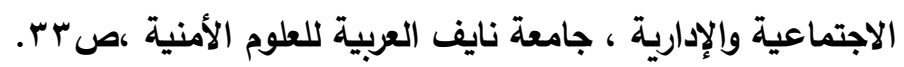

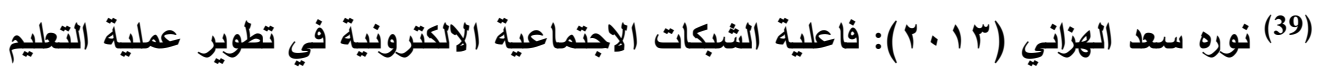

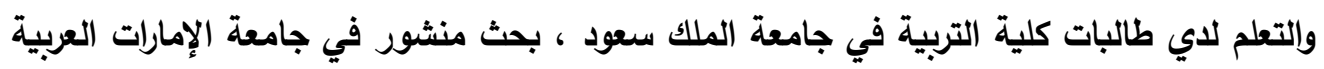

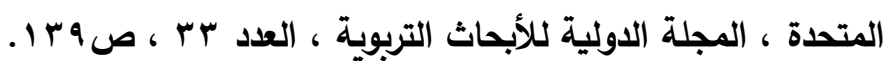

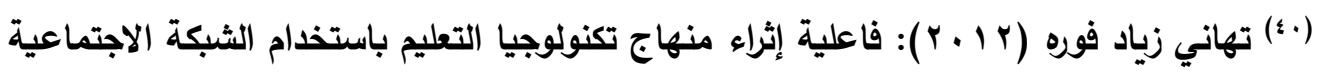
Face book الإسلامية بغزة ،رسالة ماجستير ،جامعة غزة ،كلية التربية .

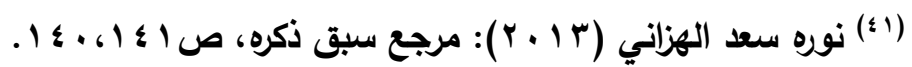

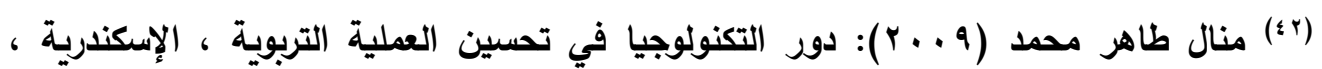

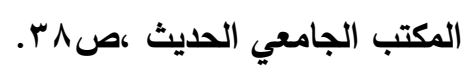
(43) Mason, L. H. (2011) "Face book Fringing and Faculty Students Student Communication, Cutting-edge Technology in Higher Education. Vol. 3. pp. 61 - 87.

(4 ؛) احمد شفيق السكري (10 ـ r) : الخدمة الاجتماعية المعاصرة ، الإسكندرية ، دار الوفاء لانيا

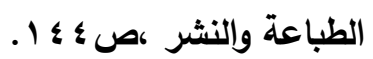

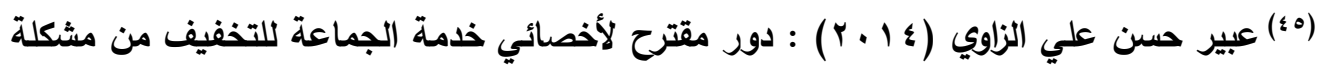

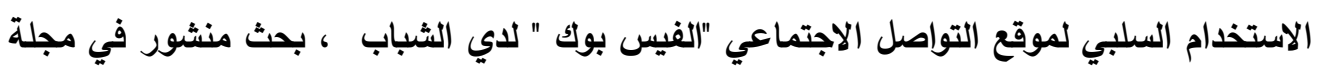

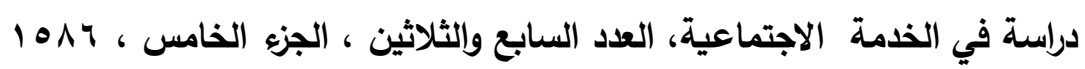

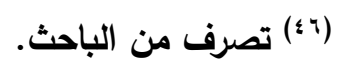
(v) عادل بن عايد المغني : ضوابط التواصل الاكتروني من منظور إسلامي ومدي تحققها لاي

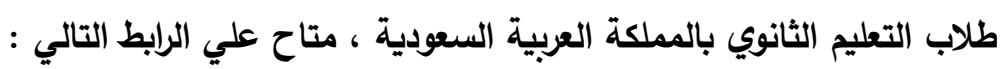
https://www.google.com.eg/search?q=facuity \% 20download \% 20fid\% 204 4765

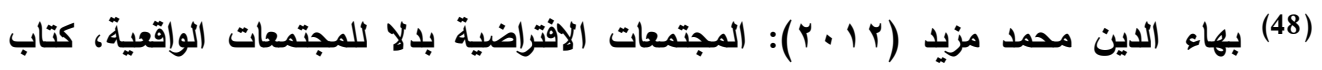

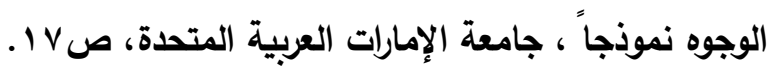

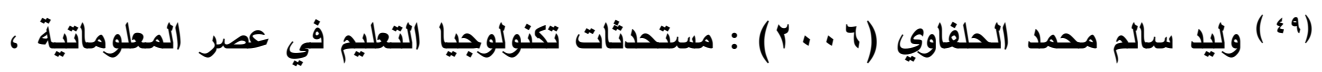

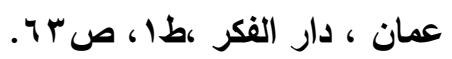




\title{
Role of Social Media Networks in Enhancing the Educational process
}

\author{
Sherif Abdullah Abdo Ismail
}

\begin{abstract}
:
The Internet is one of the most prominent innovations in communication technology that has imposed itself on the global level, until it has become a method of daily dealing and a pattern of knowledge exchange between peoples, and some have called our modern age the Internet era or the era of the information revolution because of the profound effects this network has brought about and radical changes in methods and forms. Communication in all aspects of life.

Electronic communication groups through social networks are a new reality in our society, through which a large group of people interact, who do not fall within a single geographical framework. Rather, all that unites them is a common interest. These groups have succeeded in attracting many individuals to engage in them. Groups do not require the individual either to know how to deal with network sites, by pressing a keyboard and sitting in front of a screen, the individual crosses the boundaries of reality and breaks away from its real context and turns into a new social context, which is virtual reality.
\end{abstract}

Key Words: E-Learning, e-training, Social networks. 